NBER WORKING PAPER SERIES

\title{
GENERAL EQUILIBRIUM EFFECTS OF CASH TRANSFERS: EXPERIMENTAL EVIDENCE FROM KENYA
}

\author{
Dennis Egger \\ Johannes Haushofer \\ Edward Miguel \\ Paul Niehaus \\ Michael W. Walker \\ Working Paper 26600 \\ http://www.nber.org/papers/w26600 \\ NATIONAL BUREAU OF ECONOMIC RESEARCH \\ 1050 Massachusetts Avenue \\ Cambridge, MA 02138 \\ December 2019, Revised October 2021
}

Niehaus is a co-founder, former president (2012 - 2017) and chairman (without compensation) of the board of GiveDirectly. Haushofer is the founder and a board member (uncompensated) of the Busara Center for Behavioral Economics. We thank the study participants for generously giving their time; Justin Abraham, Aakash Bhalothia, Christina Brown, Genevieve Deneoux, Tilman Graff, Max Lauletta, Michelle Layvant, Layna Lowe, Anya Marchenko, Gwyneth Miner, Max Mueller, Priscilla de Oliviera, Robert On, Rachel Pizatella-Haswell, Emaan Siddique, Zenan Wang, Francis Wong and Kejian Zhao for excellent research assistance; Innovations for Poverty Action for data collection fieldwork; the Busara Center for Behavioral Economics for piloting work; GiveDirectly for fruitful collaboration; and Martin Aragoneses, Vittorio Bassi, Abhijit Banerjee, Chris Blattman, Giacomo DiGiorgi, Esther Duflo, Yuriy Gorodnichenko, Seema Jayachandran, Adriana Lleras-Muney, Atif Mian, Emi Nakamura, Ben Olken, Jon Steinsson, numerous conference and seminar participants, and three anonymous referees and the Editor (D. Donaldson) for comments. This research was supported by grants from the National Science Foundation, International Growth Centre, CEPR/Private Enterprise Development in Low-Income Countries (PEDL), the Weiss Family Foundation, and an anonymous donor. The GiveDirectly program was supported by The Pershing Square Foundation. Walker gratefully acknowledges financial support from the NSF Graduate Research Fellowship (Grant No. DGE 1106400). The study received IRB approval from Maseno University and the Univ. of California, Berkeley. AEA Trial Registry RCT ID: AEARCTR-0000505.

NBER working papers are circulated for discussion and comment purposes. They have not been peer-reviewed or been subject to the review by the NBER Board of Directors that accompanies official NBER publications.

(C) 2019 by Dennis Egger, Johannes Haushofer, Edward Miguel, Paul Niehaus, and Michael W. Walker. All rights reserved. Short sections of text, not to exceed two paragraphs, may be quoted without explicit permission provided that full credit, including (C) notice, is given to the source. 
General Equilibrium Effects of Cash Transfers: Experimental Evidence from Kenya Dennis Egger, Johannes Haushofer, Edward Miguel, Paul Niehaus, and Michael W. Walker NBER Working Paper No. 26600

December 2019

JEL No. E62,H3,O12,O23,R13

\section{ABSTRACT}

How large economic stimuli generate individual and aggregate responses is a central question in economics, but has not been studied experimentally. We provided one-time cash transfers of about USD 1000 to over 10,500 poor households across 653 randomized villages in rural Kenya. The implied fiscal shock was over 15 percent of local GDP. We find large impacts on consumption and assets for recipients. Importantly, we document large positive spillovers on nonrecipient households and firms, and minimal price inflation. We estimate a local transfer multiplier of 2.4. We interpret welfare implications through the lens of a simple household optimization framework.

Dennis Egger

University of California, Berkeley

Department of Economics

530 Evans Hall \#3880

Berkeley, CA 94720-3880

dennistegger@berkeley.edu

Johannes Haushofer

Department of Economics

Stockholm University

Universitetsvägen $10 \mathrm{~A}$

Stockholm 10691 Sweden

and Busara Center for Behavioral Economics,

Nairobi, Kenya

and also NBER

johannes.haushofer@ne.su.se

Edward Miguel

Department of Economics

University of California, Berkeley

530 Evans Hall \#3880

Berkeley, CA 94720

and NBER

emiguel@econ.berkeley.edu
Paul Niehaus

Department of Economics

University of California, San Diego

9500 Gilman Drive \#0508

La Jolla, CA 92093

and NBER

pniehaus@ucsd.edu

Michael W. Walker

University of California, Berkeley

Center for Effective Global Action

714B Giannini Hall

Berkeley, CA 94720

mwwalker@berkeley.edu

A randomized controlled trials registry entry is available at https://www.socialscienceregistry.org/trials/505

An appendix is available at

http://www.nber.org/data-appendix/w26600 


\section{Introduction}

Tracing out the pattern of transactions in an integrated economy, and their contribution to aggregates of interest like overall output or well-being, has long been a central task of economic analysis. For instance, there has been interest in understanding the aggregate impacts of fiscal stimulus and cash infusions for decades (Keynes 1936), and a growing body of empirical evidence from rich countries shows that fiscal multipliers can sometimes be positive and large, based on non-experimental variation generated by policy changes Chodorow-Reich 2019; Nakamura and Steinsson 2014; Suarez Serrato and Wingender 2016; Auerbach, Gorodnichenko, and Murphy 2020). Until now, however, these issues have not been subjected to experimental examination.

There is also renewed interest in related topics in development economics with the rise of large-scale cash transfer programs, which have now been implemented in scores of low and middle income countries $]^{1}$ A large literature on the impacts of these transfers has developed, employing well-identified experimental and quasi-experimental designs. These studies have documented effects on a broad range of behavioral responses among treated households, including consumption, earnings, assets, food security, child growth and schooling, selfreported health, female empowerment, and psychological well-being (Haushofer and Shapiro (2016), Baird, McIntosh, and Ozler (2011), and Bastagli et al. (2016)). Yet there is limited evidence on the aggregate economic impacts or welfare consequences of such policies (for exceptions, see Angelucci and De Giorgi (2009), Cunha, De Giorgi, and Jayachandran (2018), and Filmer et al. (2018)).

The present study was prospectively designed to unite these two disparate literatures by experimentally studying the aggregate impacts of large cash stimulus programs. We designed and carried out a large-scale experiment in rural Kenya that provided one-time cash transfers worth roughly USD 1000 (distributed by the NGO GiveDirectly) to over 10,500 poor households in a sample of 653 villages with a population of roughly 300,000. The implied fiscal shock was large, as the cash transfers amounted to over $15 \%$ of GDP in treatment villages during the peak 12 months of the program.

Beyond its fiscal scale, at least three aspects of the project represent advances on most existing work. First, we generated substantial spatial variation in the intensity of transfers by deliberately randomizing the allocation of cash transfers not just across households or villages (as is typical), but also across geographic sublocations (groups of 10-15 villages), thereby increasing our ability to detect aggregate impacts. Second, we carried out unusually

1. $97 \%$ of developing countries in Europe, Latin America and Sub-Saharan Africa have some type of cash transfer program (World Bank 2017). 
extensive original data collection, giving us greater visibility into the chain of causal effects linking cash transfers to aggregate outcomes in a complex and interconnected economy. Our household and enterprise censuses of the study area count 65,385 households and 12,095 nonfarm enterprises. Within this unusually large sampling frame, we gathered detailed panel (longitudinal) data on household receipt of the transfer; household consumption expenditure patterns (representative for both recipient and non-recipient households); local enterprise production, employment and revenue; labor market conditions; as well as especially highfrequency (monthly) and spatially disaggregated market data on prices. Third, we interpret the results through the lens of a theoretical framework that highlights the links between the individual empirical results, the aggregate transfer multiplier, and welfare in this setting.

Following earlier studies, we first document large direct impacts on households that received transfers, including increases in consumption expenditures and holdings of durable assets eighteen months after the start of transfers. We do not observe meaningful changes in total labor supply among recipient households.

Enterprises in areas that receive more cash transfers also experience meaningful revenue gains, in line with the increases in household expenditure. Interestingly, sales increased without noticeable changes in firm investment behavior (beyond a modest increase in inventories), and did not increase differentially for firms owned by cash recipient households relative to non-recipients. Both patterns suggest a demand- rather than investment-led expansion in economic activity. Increased enterprise revenue in turn translates into moderate increases in wage bills and profits. Methodologically, one important feature of the enterprise (and to a lesser extent household) results is that they are largely driven by the overall intensity of treatment in nearby communities, not solely by the treatment status of the village in which the enterprise is located. This suggests that common study designs which aim to identify spillover effects by clustering treatment at the village level and assuming no spillovers across villages may be mis-specified, at least in densely populated areas such as the one we study ${ }^{2}$

Despite not receiving transfers, non-recipient households also exhibit large consumption expenditure gains: their annualized consumption expenditure is $13 \%$ higher eighteen months after transfers began, an increase roughly comparable to the gains contemporaneously experienced by the recipient households ${ }^{3}$ Increased spending is not financed by dissaving, but more likely results in part from the income gains experienced by local firms' owners and workers. Indeed, non-recipients' income gain is driven largely by increases in wage labor earnings, consistent with the fact that enterprise wage bills increase. In a reassuring check,

2. For example, households are located within $2 \mathrm{~km}$ of seven other villages on average.

3 . We note below that consumption gains among recipient households are likely to have been larger in the period immediately following transfer receipt. 
the magnitude of per capita consumption gains among local households lines up roughly with the per capita revenue gains among local firms. On some level this is unsurprising, as increases in local consumption expenditures were spent somewhere; our contribution is to carefully document how such spending spreads locally through a low-income economy.

A further issue is the extent to which transfers affect local prices (as for example Cunha, De Giorgi, and Jayachandran (2018) show in Mexico), and thus the extent to which the effects described above are nominal or real. We study this question through careful monthly measurement of prices for scores of local commodities, consumer goods, and durable goods, as well as prices for inputs like labor and capital. For inputs, we find positive point estimates, but they are economically moderate in magnitude and not always statistically significant. For outputs, we document statistically significant, but economically minimal, local price inflation. Average price inflation is $0.1 \%$, and even during periods with the largest transfers, estimated price effects are less than $1 \%$ and precisely estimated across all categories of goods.

We next ask what these effects imply for the aggregate level of economic activity, computing a local transfer multiplier. A standard macroeconomic framework would predict that large multipliers are possible in our rural Kenyan setting: it is a largely closed local economy within a currency union receiving external transfers, with incomplete markets and a large share of hand-to-mouth consumers (Farhi and Werning 2016). Using an expenditure-based approach that takes advantage of our data on the consumption expenditures of representative samples of both recipient and non-recipient households as well as investment by local firms, we estimate a local transfer multiplier of 2.5. A dual income-based approach, relying on distinct and complementary measures of labor and capital income, enterprise profits, and taxes, yields a similar estimate of 2.3. These estimates are broadly in line with what a simple model would imply from households' marginal propensity to consume local value added, which we estimate to be approximately 0.76 over the study period. These results contribute to an active recent empirical literature that estimates multipliers. 4

A core contribution of this study is thus to exploit a randomized experiment to estimate an important macroeconomic quantity (see Muralidharan and Niehaus (2017) for a related discussion). A notable aspect of our approach is the fact that transfers came from donors out-

4. Our estimates are somewhat larger than those from a structural simulation, which predicted that the local multiplier from cash transfers in rural Kenya could range from 1.6 to 1.9 (Thome et al. 2013), and are similar in magnitude to non-experimental estimates from a cash transfer program in Mexico (1.5 to 2.6) (Sadoulet, Janvry, and Davis 2001). They are also somewhat larger than recent estimates of the fiscal spending multiplier (which is distinct from the transfer multiplier, since households can save part of the transfer) derived from cross-sectional US policy variation, which often range from 1.5-2.0 (Chodorow-Reich 2019), and from Brazil, which are close to 2 (Corbi, Papaioannou, and Surico 2019). Pennings (2021) focuses on the US transfer multiplier. Kraay (2014) estimates fiscal multiplier estimates less than one when donor lending is used as an instrument for national government spending in developing countries. 
side the study area, rather than being internally tax- or debt-financed; the latter is typically the case in the US programs studied, and may complicate the interpretation of consumption responses due to contemporaneous tax incidence or Ricardian equivalence issues. The targeting of the transfers to just one region within the larger Kenyan economy also allows us to abstract away from monetary policy and exchange rate responses, simplifying analysis relative to the study of national stimulus policies. A limitation of our approach is that we observe partial data in the months immediately following the transfers, which reduces the precision of some estimates.

Few existing treatments of multipliers also explicitly examine their welfare implications $5^{5}$ We interpret the welfare implications of our results using a simple theoretical framework. Transfers directly increase the welfare of those who receive them by $\$ 1$ per $\$ 1$ received. General equilibrium effects impact welfare through two additional channels: changes in household budget sets (due for example to changes in wages, prices, or firm profits), and changes in peer behaviors that enter directly into own utility (due to externalities or public good provision). The value of budget set expansions depends on what drives them: expansions due to increases in productivity are worth $\$ 1$ per $\$ 1$, while expansions due to increased factor supply (e.g., labor) come at a partially offsetting opportunity cost. Interpreted through this lens, the results generally suggest that non-recipients were made better off by an expansion in their budget sets driven largely by increased factor productivity, as opposed to factor supply. Externality effects are positive or null, with one possible exception: positive spillovers were large enough that village-level asset inequality increased slightly, which may affect well-being if households have preferences over their relative socioeconomic standing.

The constellation of findings raises an intriguing question about how the economy absorbed such a large shock to aggregate demand, and in particular how it did so without correspondingly large increases in the employment of land (which is in fixed supply), labor, or capital. One plausible, albeit speculative, possibility is that the utilization of these factors was "slack" in at least some enterprises (Lewis 1954). This seems plausible because in the retail and manufacturing sectors, where output responses were concentrated, the typical firm has a single employee (i.e., the proprietor), suggesting that integer constraints may often bind. In addition, many enterprises operate "on demand" in the sense that they produce only when they have customers, and the average non-agricultural enterprise sees just 1.9 customers per hour. In addition to retail, much manufacturing in this setting is on demand; for example, a mill owner waits for customers to bring their grain. The existence of slack may help account for the large multiplier we estimate, as has also recently been argued in US data (Michaillat and Saez 2015; Murphy 2017$)$.

5. Recent and notable exceptions include Mankiw and Weinzierl (2011) and Sims and Wolff (2018). 


\section{Study design}

\subsection{Setting: rural western Kenya}

The study took place in three contiguous subcounties of Siaya County, a rural area in western Kenya bordering Lake Victoria. The population in Siaya is predominantly Luo, the second largest ethnic group in Kenya, and while rural it is also relatively densely populated, with 395 people per $\mathrm{km}^{2}$ compared to a Kenyan average of 91 . The main national road running from the port of Mombasa to Nairobi and on to Kampala passes through the study area, likely helping to integrate it into the regional economy.

The NGO GiveDirectly (GD) selected the study area based on its high poverty levels. Within this area GD selected rural (i.e., not peri-urban) villages in which it had not previously worked ${ }^{6}$ This yielded a final sample of 653 villages spread across 84 sublocations (the administrative unit above a village). The mean village consists of 100 households, and at baseline, the average household had 4.3 members, of which 2.3 were children. The average survey respondent was 48 years old and had about 6 years of schooling. $97 \%$ of households were engaged in agriculture; at endline, $49 \%$ of households in control villages were also engaged in wage work and $48 \%$ in self-employment.

Transfers and data collection took place from mid-2014 to early 2017, a period of steady economic growth, relative prosperity, and political stability in Kenya. The World Bank reports annual per capita GDP growth rates ranged between 2.4 to 3.4 percent. All data collection concluded months prior to the August 2017 national election.

\subsection{Intervention: The GiveDirectly (GD) Cash Transfer Program}

GD provides unconditional cash transfers to poor households in low-income countries. For the purpose of this study, to be eligible for transfers, households had to live in homes with thatched roofs, a simple means-test for poverty. In treatment villages, GD enrolled all households that met this criterion ("eligible" households) as classified by their field staff through a village census, and confirmed via two additional visits (see Appendix B.1).

Approximately one-third of all households were eligible. These households received a series of three transfers totaling KES 87,000, or USD 1,871 PPP (USD 1,000 nominal), via the mobile money system M-Pesa, which is widely used in Kenya. (Registering for MPesa was a prerequisite for receiving transfers; households without a mobile phone were given the option to purchase one from GD staff with the cost deducted from their transfer.) Households selected the member they wished to receive the transfers. The total transfer

6. The listing of villages was based on the 2009 National Population Census; enumeration areas (which typically correspond to a single village) were treated as villages by GD and this study. 
is large, corresponding to 75 percent of mean annual household expenditure in recipient households. In aggregate, the transfers were equivalent to approximately 17 percent of annual GDP (based on our data described below) in the treated areas during the peak 12 months of disbursements, and to 24 percent of annual GDP during the full 24 month rollout period. Although small in relation to overall Kenyan GDP in $2015(<0.1 \%)$, locally this is thus a larger relative shock than most government transfer programs, e.g., the ARRA programs studied in the recent US fiscal multiplier literature, see Chodorow-Reich (2019).

Transfers were made in a series of three payments as follows: a token transfer of KES 7,000 (USD 151 PPP) was sent once a majority of eligible households within the village had completed the enrollment process, followed two months later by the first large installment of KES 40,000 (USD 860 PPP). Six months later (and eight months after the token transfer), the second and final large installment of KES 40,000 was sent. The median treated household received its token transfer 47 days after being registered for the program; transfers should be interpreted as anticipated during that period to the extent recipients believed GD's promises $]^{7}$ The transfers were non-recurring, i.e., no additional financial assistance was provided to recipient households after their final installment, and they were informed of this up front. Households in control villages did not receive transfers.

\subsection{Experimental design}

To identify spillovers both within and across villages, we employed a two-level randomization design (Figure A.1, Panel A). First, we randomly assigned sublocations (or in some cases, groups of sublocations) to high or low saturation status, resulting in 33 high- and 35 lowsaturation groups. Within high (low) saturation groups we then randomly assigned twothirds (one-third) of villages to treatment status. We also randomized the order in which treatment was rolled out to treated villages. Within treatment villages, all eligible households received a transfer 8 This design induces variation in treatment intensity across space due both to the variation in sublocation treatment intensity, and random variation in the location of treated villages within sublocations. Figure A.2 illustrates that there is considerable

7. The precise timing of the first transfer was uncertain, and we believe that recipients may also have perceived the first transfer as less certain than the subsequent ones. However, we do not know of any borrowing against future GD payments, and credit markets are imperfect in our context. In the earlier GiveDirectly study, Haushofer and Shapiro (2016) find evidence for both savings and credit constraints: households that received lump-sum transfers were more likely to own large durable assets at endline than households receiving monthly transfers, even though the total transfer amounts were the same. This suggests that households had trouble borrowing against the promise of the future transfer and saving the early installments. This is also consistent with US evidence finding no anticipation in advance of the receipt of economic stimulus payments (Broda and Parker 2014). We therefore consider all transfers symmetrically in our dynamic regressions and leave analysis of potentially differing effects across installments for future work.

8. Full details of the randomization are in Appendix B.2. 
variation both across and within sublocations in the share of neighboring villages treated $!^{9}$

\section{Data and empirical specifications}

We conducted four types of surveys, of households, enterprises, market prices, and local public goods. Results from the public goods surveys are presented primarily in a separate paper (Walker 2018), and discussed briefly here. We filed several pre-analysis plans for this project; for details on the PAPs and where we go beyond these plans, see Appendix I.

\subsection{Household data}

We first conducted a baseline household census in all villages, which serves as a sampling frame and classifies household eligibility status. The census was designed to mimic GD's censusing procedure but was conducted by independent (non-GD) enumerators across both treatment and control villages for consistency. Throughout this paper, we base our analysis on village membership, household definitions and eligibility as classified by our project data collection field staff. In all, the census identified 65,385 households with a total baseline population of 280,000 people in study villages.

We conducted baseline household surveys within one to two months after the census and before the distribution of any transfers to a village (Figure A.1, Panel B) ${ }^{10}$ We used census information to sample at random eight eligible and four ineligible households per village to survey. When households contain a married or cohabiting couple, we randomly selected one of the partners as the target survey respondent. Due to time and budget constraints, we sought to complete all baseline household surveys in a single day. If a household on our sampling list was not available on that day, we instead surveyed a randomly-selected replacement household with the same eligibility status. We conducted a total of 7,848 baseline household surveys between September 2014 and August 2015.11 The survey contained detailed modules on economic activities, asset ownership, psychological well-being, health and nutrition. A large array of baseline characteristics are balanced across treatment and control villages (Table C.2, column 2).

Endline household survey data was collected between 9 and 31 months after each household's "experimental start date," meaning the month in which transfers were expected to

9. Figure B.1 provides a higher-resolution example for two villages.

10. In a few cases, baseline surveys were conducted before the distribution of transfers but after GD had held meetings in the village informing households that it would be a treatment village.

11. Of this total, 6,510 households were on the initial sampling list, and 1,338 were randomly-selected replacement households. 
start in a village assigned to treatment, regardless of their actual treatment timing 12 The 5th/95th percentiles of timing ranged from 12 to 27 months, and the median survey was conducted 19 months after the experimental start month, or about 11 months after the distribution of the last lump sum transfer (Figure A.1, Panel B). This timing implies that some but relatively few households were surveyed in the months immediately following cash transfer receipt, an issue we return to below when estimating the transfer multiplier.

Endline household surveys targeted all households on the initial sampling lists (including those missed at baseline), along with replacement households that were surveyed at baseline. For households that had been surveyed at baseline, we attempted to survey the individual who was the baseline respondent. We conducted a total of 8,242 endline household surveys between May 2016 and June 2017 ${ }^{13}$ We achieved high tracking rates at endline, reaching over $90 \%$ of eligible and ineligible households in both treatment and control villages, and these rates do not systematically vary by treatment status (Table C.1). The only subgroup difference of note is that we are slightly less likely to find ineligible households that were initially surveyed at baseline in high saturation sublocations (see Appendix C.2 for more information). In addition to the baseline modules, endline surveys collected more detailed data on household expenditures and crop production, additional psychological scales (in particular, related to stress and hope), and female respondents surveyed by a female enumerator were also administered a module on female empowerment and gender-based violence.

\subsection{Empirics: recipient households}

If the general equilibrium effects of transfers were fully contained within administrative units (here, villages and sublocations), then an appropriate specification would be

$$
y_{i v s}=\alpha_{1} \text { Treat }_{v}+\alpha_{2} \text { HighSat }_{s}+\delta_{1} y_{i v s, t=0}+\delta_{2} M_{i v s}+\varepsilon_{i v s}
$$

where $y_{\text {ivs }}$ is an outcome of interest for household $i$ in village $v$ in sublocation $s .14$ Treat is an indicator for residing in a treatment village at baseline, and HighSat an indicator for being in a high-saturation sublocation. Here $\alpha_{1}$ captures the total average treatment

12. The order in which villages were visited by GD and the research team was randomized within subcounties. We calculate the start and end months of when GD started transfers to villages within a subcounty, and then, across these months, evenly assign both treatment and control villages experimental start months based on the random ordering.

13. This includes 7,019 initially sampled and 1,223 replacement households. Of the initially sampled households, 1,015 had been missed at baseline. The main analysis focuses on the "initially sampled" (which includes those missed at baseline) and "replacement" households; results are similar using only originally sampled households (available upon request).

14. When we examine individual-level outcomes using Equation (1), we define treatment status and eligibility on the basis of the household in which the individual lives. 
effect for households in treatment versus control villages, including both the direct effect of treatment (for eligible households) and any within-village spillovers; note that our design does not allow us to identify these separately. $\alpha_{2}$ is a relatively coarse way to assess crossvillage spillovers, as it does not utilize all experimental variation. We include the baseline value of the outcome variable $\left(y_{i v s, t=0}\right)$, when available, to improve statistical precision ${ }^{15}$ We cluster standard errors at the village level, and weight observations by inverse sampling probabilities to be representative of the population of eligible households.

Overall, we view Equation 1 as a useful benchmark but unlikely to capture well the spatial variation in treatment intensity evident in Figure A.2. This is because in our study area villages are relatively close to each other; sublocation boundaries are not "hard" in any sense nor reflective of salient ethnic or social divides; and because our data indicate that there is extensive economic interaction in nearby markets regardless of sublocation. To better capture spillovers, we therefore estimate models in which a household's outcomes depend on the amount of money distributed in its own and other geographically proximate villages:

$$
y_{i v}=\alpha+\beta A m t_{v}+\sum_{r=2}^{R} \beta_{r} A m t_{v, r}^{\neg v}+\delta_{1} y_{i v, t=0}+\delta_{2} M_{i v}+\varepsilon_{i v}
$$

The novel terms here are the amount $A m t_{v}$ of cash per capita transferred to one's own village $v$ over the entire study, and the amount $A m t_{v, r}^{\neg v}$ of cash per capita transferred to villages other than $v$ in a series of bands with inner radius $r-2 \mathrm{~km}$ and outer radius $r \mathrm{~km}$ around the village centroid. We normalize both to be measured as a share of per capita GDP ${ }^{16}$ The Amt variables depend on both the random assignment of villages to treatment and also on the endogenous share of households in those villages eligible for transfers, so we instrument for them using the own-village treatment indicator Treat $t_{v}$ and the share $s_{\neg, t, r}^{e, t}$ of eligible households in each band assigned to treatment. For brevity, we do not report IV first-stage results; however, the minimum first-stage Sanderson-Windmeijer F-statistic is 107.9 across all the cross-sectional specifications (Tables 1.3) and 88.4 in the multiplier specifications below, minimizing concerns about weak instruments. To account for spatial correlation, we calculate standard errors using a uniform kernel up to $10 \mathrm{~km}$ (Conley 2008). ${ }^{17}$

15. For observations where the baseline value is missing, we include an indicator variable equal to one denoting a missing value $\left(M_{i v s}\right)$, and set the baseline value of the outcome variable equal to its mean.

16. We use an expenditure-based measure of GDP that is described in Section 5, which we convert to a per-capita measure based on household census data from our study area, and augmented with data from the GiveDirectly census and the 2009 Kenya National Population Census when necessary. Per capita GDP in low saturation control villages is 637 USD PPP (2727 USD PPP per household); see Appendix B.3.

17. We also conduct Fisher randomization tests for all specifications, where we re-randomize cash transfers across sublocations and villages as well as their roll-out over time as in our experiment and test against the sharp null that effects are zero. Conclusions are robust to this alternative method of inference. 
Because we had no a priori knowledge of the relevant distances over which general equilibrium effects might operate, we pre-specified an approach in which we first estimate a series of nested models varying the outer limit $R$ of the spatial bands from $2 \mathrm{~km}$ to $20 \mathrm{~km}$ in steps of $2 \mathrm{~km}$, and then select the one which minimized the Schwarz Bayesian Information Criterion (BIC). We report estimates of Equation (2) using the selected outer limit $\bar{R}$. As it turns out, this algorithm selects only the innermost $0-2 \mathrm{~km}$ band for almost all outcomes ${ }^{18}$

Equation (2) correctly identifies the overall effects of the intervention if transfers delivered outside the radius $\bar{R}$ have no effect on $i$. If not - if, for example, all households were affected to some extent by all transfers in the study area - then the estimated effects are relative to these "ambient" effects. The BIC selection procedure determines how reasonable this identifying assumption is by omitting ring $R+2$ from the model if it has little explanatory power for the outcome. In principle, this could be either because variation in treatment intensity at that distance has a precisely estimated but small effect on the outcome (in which case it is a good "control"), or because there simply is not much variation in treatment intensity at that distance (in which case we cannot be sure). Given this, it is important to note that our design generates substantial variation in treatment intensity even at larger distances. Transfers in the $2 \mathrm{~km}$ buffer, which the BIC always includes, range from 0 to $27 \%$ of GDP, with a 10-90 percentile range of $[4 \%, 15 \%]$. Even in the 4 to $6 \mathrm{~km}$ buffer, which the BIC never selects for any primary outcome, the 10-90 percentile range remains wide, at $[3 \%$, 10\%]. This suggests that a subset of our villages can reasonably serve as "pure controls."

We also examine in Appendix $\mathrm{F}$ how sensitive our main conclusions are to fixing larger maximal radii $\bar{R}$ than the BIC selects, which implies a more conservative definition of the "control group." While there is some variation from outcome to outcome, overall the effects are quite stable as we add the $2-4 \mathrm{~km}$ band and fairly stable as we add the $4-6 \mathrm{~km}$ band, though as expected standard errors often become much larger. We generally cannot reject that these estimates are different statistically from those estimated using the BIC-optimal bandwidth, giving us greater confidence in the latter. Finally, note that we typically estimate spillovers of the same 'sign' as the direct effects, which suggests that any remaining bias in our estimates likely leads us to understate, rather than overstate, overall effects. All told,

18. Note that this model selection step introduces some circularity, as we first determine the distances at which effects occur, and then estimate effects at those distances. We check that inference is robust to this model selection, and to alternative approaches more generally. First, we calculate exact $p$-values using a Fisher permutation test (i.e. randomization inference, see Appendix F.4). Second, we conduct repeated 50-50 splits of the data into training and test sets, using the training data from each split to perform the BIC step and the test set to estimate parameters, and record the proportion of times that the resulting estimates lie within the $95 \%$ confidence intervals we report here (Appendix F.2). Third, we estimate effects holding the spatial radius fixed at $2 \mathrm{~km}, 4 \mathrm{~km}$, and $6 \mathrm{~km}$, respectively, thus eliminating the model selection step (Appendix F.1). Taken together, these results provide reassurance that our methods yield valid inferences. 
we view the problem of estimating spatial effects as unlikely to admit a perfect solution, but believe that our study design and econometric specification allow us to advance meaningfully relative to most existing work.

We estimate Equation (2) for all eligible households and then use it to obtain estimates of the total effect on recipient households, which we report as "Recipient Households" in tables. By "total effect" we mean how the households' outcomes differ from what they would have been in the absence of the intervention. We calculate these by multiplying the estimated coefficients from Equation (2) by the average values of the regressors, i.e.,

$\hat{\beta} \cdot\left(\overline{A m t}_{v} \mid i\right.$ is an eligible recipient $)+\sum_{r=2}^{\bar{R}} \hat{\beta}_{r} \cdot\left(\overline{A m t}_{v, r}^{\neg v} \mid i\right.$ is an eligible recipient $)$ for all radii bands up to the selected $\bar{R}$. This effect allows for across-village spillovers in addition to direct effects and within-village spillovers 19 As a benchmark, we also report estimates of $\alpha_{1}$ from Equation (1), which is the total treatment effect if all spillovers are contained within villages (a common identifying assumption).

\subsection{Empirics: non-recipient households}

We use an analogous approach to estimate total effects on non-recipient households, which include both eligible households in control villages and ineligible households in all villages. Specifically, we estimate

$$
y_{i v}=\alpha+\sum_{r=2}^{\bar{R}} \beta_{r}^{1} A m t_{v, r}+\sum_{r=2}^{\bar{R}} \beta_{r}^{2}\left(A m t_{v, r} \cdot \text { Elig }_{i v}\right)+\gamma \text { Elig }_{i v}+y_{i v, t=0} \cdot \delta+\varepsilon_{i v}
$$

This specification modifies Equation (2) as follows. First, because non-recipient households do not experience direct effects, we no longer separate own-village effects and across-village spillovers: we drop $A m t_{v}$ and replace $A m t_{v, r}^{\neg v}$ with $A m t_{v, r}$, so that spillovers work entirely through $\beta_{r}^{1}$ and $\beta_{r}^{2}$. Second, we include an indicator for eligibility status and its interaction term with amounts to allow for spillovers to differ by eligibility status (recall that eligible households in control villages are non-recipients). As above, we instrument for $A m t_{v, r}$ using the share of eligible households assigned to treatment within the corresponding band, i.e., $s_{v, r}^{e, t}$ and $s_{v, r}^{e, t} \cdot$ Elig $_{i v}$ for each radii band $v$. When available, we include the baseline value of the outcome variable. We report the average total effect on non-recipients as a population-

19. Appendix C.5 provides an example of this for outcomes in Table 1. We also consider the possibility that effects are non-linear in the per-capita amounts transferred. Figure A.3 presents non-linear estimates of equation 2 for two key outcomes, total consumption and firm revenue. The relationships appear roughly linear, and we cannot formally reject linearity. We conduct the same test for our 10 pre-specified primary outcomes and eligible / ineligible households separately, and cannot reject linearity at the $10 \%$ significance level for any of them. 
weighted average of effects for the two groups 20

\subsection{Enterprise data}

We employ several complementary sources of data on enterprises. First, we use detailed agricultural and self-employment modules from the household surveys. The agriculture module covers crop-by-crop agricultural production, sales, employment, and input costs; the selfemployment module covers revenues, profits, hours worked, and some costs and investments for enterprises run by household members. These data are representative of enterprises owned locally (i.e., by residents of the study area) and allow us to clearly attribute profits to their residual claimants. They do not capture enterprises owned by people living outside the study area, which we capture separately through the enterprise census and surveys.

Specifically, we conducted censuses and surveyed a representative subset of all non-farm enterprises at baseline and endline (see Appendix D for details). The endline census was conducted between November 2016 and April 2017, covering both enterprises identified at baseline and newly established enterprises. This served as the endline survey sampling frame; we randomly sampled up to 5 enterprises per village, stratified by those operating from within and outside of homesteads. Surveys covered revenue, profits, employees, wages, some other costs, and taxes paid. The main endline sample includes 1,699 enterprises operated from within and 1,442 from outside the homestead (both from enterprise surveys), as well as 7,899 agricultural enterprises from the household survey. Enterprise characteristics appear balanced across treatment and control villages at baseline (Table D.3): there are no statistically significant differences at the $5 \%$ level, and two of 18 are significant at $10 \%$, which we would expect by chance.

This integrated approach to household and enterprise surveying allows us to match firms to their owners. We match all agricultural enterprises (as found via household surveys), and $56 \%$ of non-agricultural enterprises, for a total of $93 \%$ of all enterprises. Based on this match, we estimate that enterprise activity is highly localized, with $92 \%$ of total profits and $87 \%$ of revenues accruing to owners who live within the village in which the enterprise operates.

20. This is calculated as $s^{e, c}\left(\sum_{r=2}^{\bar{R}}\left(\hat{\beta}_{r}^{1}+\hat{\beta}_{r}^{2}\right) *\left(\overline{A m t}_{v, r} \mid i\right.\right.$ is an eligible non-recipient $\left.)\right)+$ $s^{i}\left(\sum_{r=2}^{\bar{R}} \hat{\beta}_{r}^{1} *\left(\overline{A m t}_{v, r} \mid i\right.\right.$ is ineligible $\left.)\right)$, where $s^{e, c}=1-s^{i}$ is the population share of eligible nonrecipient village households among all non-recipient households, and the $\hat{\beta}_{r}^{1}$ and $\hat{\beta}_{r}^{2}$ terms come from Equation (3). 


\subsection{Empirics: enterprises}

We estimate enterprise-level effects using versions of Equations (1) and (2), with radii bands selected as above, interacting right hand side variables with enterprise type (Appendix D.2 lists the full specifications). We include village-level means rather than enterprise-level values of the lagged dependent variable given that the enterprise surveys were repeated crosssections. We carry out estimation using inverse probability weighting, accounting for enterprise type, except in some cases where we also revenue-weight outcomes. As above, we calculate and report average total effects, weighting effects for the three enterprise types, namely, agricultural enterprises, non-farm enterprises operating within homesteads, and non-farm enterprises operating outside the home; we typically pool data across all enterprise types, except when we do not observe some outcomes for agricultural enterprises. To facilitate comparisons between the household and enterprise results, we also normalize effects as perhousehold rather than per-enterprise ${ }^{21}$ To examine extensive margin effects, we estimate village-level analogues to this approach with the total number of enterprises censused (per household) as the dependent variable.

\subsection{Price data}

We measure consumer goods prices using monthly surveys of commodity prices in local markets. These surveys were conducted over the course of 2 to 2.5 years in all 61 markets in the study area (and neighboring towns) with at least a weekly market day, for a total of 1,586 market-by-month observations and 311,138 non-missing price observations. We have market price data prior to the disbursement of any local cash transfers for all markets, providing an appropriate baseline for the panel data econometric analysis detailed below, and allowing for the inclusion of market fixed effects. These include market centers located in towns, and so will appropriately reflect the impacts of households (potentially) traveling to towns to spend their transfers. Figure A.2 shows the substantial variation in treatment intensity around markets, as well as the heterogeneity in village proximity to markets. The average village had 0.7 markets located within $2 \mathrm{~km}$ and 2.3 markets within $4 \mathrm{~km}$, again indicating the rather high density of settlement. Household respondents report an average commuting time to their preferred market of 33 minutes, where over $75 \%$ walk to the market.22

\footnotetext{
21. Specifically, we calculate $\frac{1}{n_{h h}} \sum_{g} \widehat{\Delta y}_{e}^{g} * n_{e n t}^{g}$, where $n_{h h}$ is the total number of households across all control villages (column 2) or treated villages (column 3), $\widehat{\Delta y}_{e}^{g}$ is the estimated average effect $(\hat{\beta} * \bar{X})$ for enterprise type $g$, and $n_{\text {ent }}^{g}$ is the number of enterprises of type $g$ in the control or treated villages.

22. Enterprises in markets account for $65 \%$ of non-agricultural enterprise revenue, based on a 2019 census of enterprises. We did not collect price data as comprehensively from the minority of enterprises located outside of markets and dispersed within villages, both for logistical reasons and because their products tend to be less standardized. That said, estimated impacts on the prices of two common services these enterprises
} 
Market surveys collected prices for 70 relatively homogeneous products, including food (grains, vegetables, fruit, meat), livestock (goats, sheep), hardware (nails, paint), "duka" kiosk store products (non-food and packaged food), and others (e.g., fuel, health items, household items, and farming implements). We collected quotes from three vendors of each product in each market in each month, and use the median for each product-market-month. We then calculate linear log-price indices by weighting prices by household expenditure shares ${ }^{23}$ We also examine effects on subcategories of goods, which include: food items; nonfood non-durables (such as soap, cooking fat, and firewood); durables (such as iron sheets and jerry cans used for transporting water or fuel); livestock; and temptation goods 24

We measure prices of the major factors of production using household survey data on wages, land prices, and interest rates on formal and informal borrowing and lending. Because compositional changes in these inputs may be important, we examine quantity and price effects side by side.

\subsection{Empirics: prices}

We estimate effects on consumer goods prices using both spatial and temporal variation in the amount of cash distributed around each market. In contrast to the household and enterprise data, our repeated measurement of prices, both before and after the start of cash distributions, allows us to estimate equations that include market fixed effects. These absorb any systematic price differences across markets as well as differences in the share of eligible households located around those markets, conditional on which treatment is randomly allocated so that we do not need to instrument for treatment amounts in each buffer. In Appendix E.2.3, we demonstrate robustness to using an IV approach analogous to that used with household and enterprise data. Specifically, we estimate

$$
p_{m t}=\sum_{r=2}^{\bar{R}} \sum_{l=0}^{M} \beta_{r l} A m t_{m(t-l), r}+\alpha_{m}+\lambda_{t}+\varepsilon_{m t}
$$

where $p_{m t}$ is a price outcome for market $m$ in month $t . A m t_{m(t-l), r}$ is the per-household amount transferred within band $r-2$ to $r \mathrm{~km}$ around market $m$ in month $t-l$, expressed as a

offer, tailoring and maize grinding, are if anything smaller than estimated effects on our main market price index (Table E.5).

23. We use expenditure data from the the Kenya Life Panel Survey (Baird et al. 2016) conducted in 20132014 in rural areas of Siaya and neighboring Busia county. We use the KLPS data because we did not collect a full expenditure module at baseline (due to project time and budget constraints) and prefer not to use endline expenditure data which are potentially endogenous. That said, results are nearly unchanged if we use consumption expenditure shares from non-recipient households in our endline survey.

24. The consumption expenditure measure of temptation goods includes alcohol, tobacco, and gambling. The price index includes the cost of cigarettes. 
fraction of GDP. We exploit our panel setup by conditioning on fixed effects for both markets $\left(\alpha_{m}\right)$ and months $\left(\lambda_{t}\right)$. The latter account for seasonal differences and other time trends common to all markets. We again account for spatial correlation in calculating standard errors (Conley 2008). We determine both the relevant spatial distance $R$ and the relevant temporal lag $M$ over which price effects persist by minimizing an information criterion conceptually similar to that above, but adapted to account for the fact that the BIC cannot select between non-nested models (such as one with a high $R$ and another with a high $M$ ). Specifically, and as pre-specified (Appendix I), we first select $R$ while holding $M$ fixed at 3 months by estimating models of the form

$$
p_{m t}=\sum_{r=2}^{R} \beta_{r}\left(A m t_{m t, r}+A m t_{m(t-1), r}+A m t_{m(t-2), r}\right)+\alpha_{m}+\lambda_{t}+\varepsilon_{m t}
$$

where $R$ varies between $2 \mathrm{~km}$ and $20 \mathrm{~km}$. We select the value $R=\bar{R}$ that minimizes the Schwarz BIC while imposing weak monotonicity. We then select the number of monthly lags $M$ by estimating Equation (4) with $R=\bar{R}$ and choosing the model that minimizes the Schwarz BIC. This procedure selects only the 0-2 $\mathrm{km}$ band (and sometimes the 2-4 $\mathrm{km}$ band) around each market and a single temporal effect, implying that we only include contemporaneous transfers in estimating price effects. Appendix E.2 presents results for a specification where we impose $R=4 \mathrm{~km}$ and $M=18$ months for robustness, and yields similar results.

Identification in Equation (4) comes from the roll-out of treatment across space and time, and the project's research design leads to substantial variation in both dimensions. As noted above, there is considerable variation in the total amounts of cash going to the $0-2 \mathrm{~km}$ ring around each market. Moreover, the multi-year nature of the market data covers periods both of intensive transfer distribution as well as times when no transfers were going out. As above, we are unable to capture price increases that radiate throughout the whole study area (compared to neighboring counties) over the entire period, but the highly localized nature of the price effects that we do detect suggests that any such effects are unlikely to be large.

We use estimates of Equation (4) to calculate two price effects. The implied average treatment effect (ATE) is the average price effect across all markets and all months in which any transfers went out to any market in the study area, i.e., during the study period of September 2014 to March 2017. This is simply equal to the estimated coefficients multiplied by the mean of the corresponding regressors of interest. The average maximum transfer effect is the average across markets of the estimated effect in the month in which the maximum amount of cash (as a share of GDP) was distributed into the selected radii bands (in other words, out to $\bar{R}$ ) from the market. 
We focus on two sources of heterogeneous price effects. First, we classify goods into those that are more and less tradable, where the former include relatively easily transported, non-perishable items, and the latter include more difficult to transport or perishable items ${ }^{25}$ Second, we classify markets into those with better or worse market access. Standard theory in international trade predicts that more integrated markets should be less likely to experience meaningful price changes following a local aggregate demand shock. We examine output price heterogeneity with respect to a commonly used metric of market access ${ }^{26}\left(M A_{m}\right)$

$$
M A_{m}=\sum_{d} \tau_{m d}^{-\theta} N_{d} \approx \sum_{r=1}^{10} r^{-\theta} N_{r}
$$

Geographic distance $r$ is used to proxy for trade costs between origin market $m$ and destination $d$, i.e., $\tau_{m d}=r$. Destinations are $1 \mathrm{~km}$ radii bands around each market, with total population $N_{r}$ in each buffer, and we follow Donaldson and Hornbeck (2016) in setting $\theta=8$. Within quantiles of this metric, we calculate average and average maximum transfer treatment effects in the manner described above 27

We estimate effects on input prices using Equations (1), (2), and (3), as our input price data come from household surveys, and report the corresponding average treatment effects.

\subsection{Empirics: dynamics}

To estimate the multiplier, we extend the cross-sectional analysis by estimating and then integrating effects on components of GDP over time. ${ }^{28}$ For a flow variable $x$ (e.g., consumption, investment, etc.), we first estimate the following specification, which is a dynamic extension of previous estimating equations:

$$
x_{i t, v}=\alpha_{t}+\sum_{s=0}^{9} \beta_{s} A m t_{v(t-s)}+\sum_{s=0}^{9} \gamma_{s} A m t_{v(t-s), 0-2 \mathrm{~km}}^{\neg v}+\varepsilon_{i t, v} .
$$

25. For instance, more tradable goods include building materials (e.g., timber, cement, nails, iron sheets) and some household goods (soap, firewood, charcoal, batteries, washing powder), while less tradable goods include some food items (e.g., avocado, banana, cabbage, egg, pork, fish) and livestock. These classifications were undertaken based on feedback from Kenyan project staff, but there may, of course, be some ambiguity about specific items. The full pre-specified classification is in Appendix E.

26. Absent data on trade costs, we have to make an assumption about the elasticity of trade costs with respect to distance. We set the elasticity equal to 1 and conclusions are robust to alternative assumptions.

27. We also consider an alternative market access metric, namely, road access, defined as the inverse distance from the closest main road (as captured by Open Street Map), see Appendix E.2.2.

28. We stated our intention to estimate a multiplier in our pre-analysis plans but did not fully specify the econometric approach for doing so. 
where $A m t_{v(t-s)}$ is the amount transferred to village $v$ in quarter $t-s$, instrumented by a treatment indicator Treat $_{v}$ multiplied by the share of total transfers going to village $v$ in quarter $t-s$, and analogously $A m t_{v(t-s), 0-2 \mathrm{~km}}^{\neg v}$ by the share $s_{v, 0-2 \mathrm{~km}}^{e, t, v}$ of eligible households in the 0 to $2 \mathrm{~km}$ buffer around $v$ (but not in village $v$ ) assigned to treatment multiplied by the share of transfers going to that group in quarter $t-s$. The coefficients in this model are identified by the fact that village treatment status was randomized, and the timing of both cash transfers and survey data collection was rolled out to villages in a randomized order. The main challenge is that the first household surveys started around 9 months after the experimental start date in each village, while enterprise surveys began after about 18 months (see Figure A.1). With a few exceptions, recall periods are less than or equal to one month, so we often do not directly observe the initial response in flow variables in the months immediately after the first transfers went out, which is when we might expect to see some of the largest impacts on expenditure. Given that the specification treats each dollar transferred symmetrically, we can still estimate the local response during these early quarters because transfers to recipients rolled out over 8 months. Similarly, we estimate neighborhood effects using the substantial variation in the timing with which nearby villages were treated. However, we tend to obtain less precise estimates of responses in early quarters as they are estimated using less variation in treatment intensity compared to later quarters.

We then integrate dynamic effects on flow variables over time up to 29 months (10 quarters) after treatment. We compute the dynamic profile of treatment effects (or the impulse response function, IRF) using the coefficients estimated above and assuming that the treatment rolled out to recipient households as planned: the timing is a token transfer at time 0 , a first lump-sum 2 months later, and a second 8 months after the token transfer. We compute this IRF separately for recipient and non-recipient households, and separately for the three categories of enterprise in both treatment and control villages. We then aggregate the quarterly estimates across all villages (using inverse population weights from our household and enterprise census) to compute the study area-wide IRF for each flow component.

We conduct inference on the multiplier estimates this procedure yields using the wild bootstrap clustered by sublocation, the highest unit of randomization (Cameron, Gelbach, and Miller 2008). ${ }^{29}$ We focus on two one-sided hypotheses, namely, that the multiplier is less than zero and that it is less than one. We test these hypotheses using our income- and consumption-based multiplier estimates separately, as well as using the average of the two.

29. While this procedure may perform poorly in cases where most units in treated clusters are treated and there are few clusters, here at most two thirds of households in the most intensely treated clusters were treated, and there are 84 clusters, far above the 15-20 that MacKinnon and Webb (2018) deem adequate. 


\section{Tracing out the path of spending}

We now turn to tracing out the path of spending induced by the cash transfer experimental intervention. We start by documenting effects for recipient households, then for enterprises and untreated households. Monetary units are USD PPP unless otherwise defined (where the transfer was worth USD 1,871 PPP), flow outcomes are annualized, and monetary outcomes are top-coded at the 99th percentile (as pre-specified), unless otherwise noted ${ }^{30}$

\subsection{Recipient household effects}

The main household expenditure measure is the (annualized) sum of total food consumption in last 7 days, frequent purchases in the last month, and infrequent purchases over the last 12 months ${ }^{31}$ Durables expenditures are the sum of home maintenance, home improvement, and other household durables spending, and the remainder classified as non-durable spending.

As expected, recipient households report significantly higher total expenditure: USD PPP 293 more expenditure than eligible households in control villages (Table 1, column 1), an $11.5 \%$ increase over the control village in low saturation area mean of USD PPP 2,537. The estimated total treatment effect, including spatial effects, is larger at USD PPP 338, a $13.3 \%$ increase (column 2). This pattern between columns 1 and 2 is a first piece of evidence for localized, positive cross-village spillovers, which is repeated across other outcomes.

The pattern of expenditure effects by category is broadly consistent with earlier work (Haushofer and Shapiro 2016). Both non-durable and durable spending increase substantially. Food expenditure accounts for a sizable portion of the increase in non-durable expenditure in both columns (38\% and 59\%, respectively). We can reject meaningful increases in reported spending on temptation goods, consistent with Evans and Popova (2017) ${ }^{32}$

Consistent with increased expenditure on durables, asset stocks also increase (Table 1 . Panel B). Anecdotally, many recipients withdrew money from M-Pesa immediately and saved via durable assets. The main pre-specified measure of assets includes livestock; transporta-

30. The main measures were pre-specified, though some groupings vary from the PAP to ease exposition.

31. The survey was quite comprehensive. In addition to food consumption, frequent purchases include airtime and other phone expenses; internet; transport expenses (including petrol); lottery tickets and gambling; clothing and shoes; recreation and entertainment; personal toiletry and grooming; household items, such as cleaning products and candles; firewood, charcoal and kerosene; electricity; and water. Infrequent purchases include house rent/mortgage; home maintenance; home improvements; religious expenses; education expenses; charitable donations; weddings and funerals; medical expenses; household durables, including furniture, lamps, cutlery, pots and pans and other kitchen equipment; and dowry or bride price.

32. While there is likely some under-reporting of temptation goods, the fact that the control group mean is non-trivial demonstrates that at least some households feel comfortable reporting such spending. Given our limited expenditure data immediately after transfer receipt, we cannot rule out that temptation good spending increased temporarily at that time. 
tion (bicycles, motorcycles, and cars); electronics; farm tools; furniture; and other home goods; we add in net household lending to, and borrowing from, both formal and informal sources. This measure of assets increases by USD PPP 182, or $25 \%$ of the mean for eligible households in control villages in low saturation sublocations 33 This measure excludes the values of housing and land, which are harder to measure given thin local markets, but also likely important given existing work shows that households often use GD transfers to spend on housing materials (Haushofer and Shapiro 2016). We separately measure housing value as the respondent's self-reported cost to build a home like theirs, and land value as landholdings multiplied by the household's report of the per-acre cost of land of similar quality (in their village). Estimated housing value increases by USD PPP 481, or $79 \%$ of the control mean, and estimated land value increases, though this effect is not statistically significant.

Theoretically, the effect of a large-scale wealth transfer on earnings is ambiguous: it may reduce labor supply through an income effect, but may also enable productive investment or increase labor demand. In the data, recipient households' income from all sources (excluding the GD transfers) does not appear to have decreased: point estimates are positive (USD PPP 78 and 134 in the two main specifications) and the reduced form effect is marginally significant ${ }^{34}$ For labor supply specifically, we do not find that recipient households worked less; if anything, total hours worked by recipient households in agriculture, self-employment and employment increased slightly though not significantly (Table 2, Panel A, columns 1 and 2). This is consistent with the studies reviewed by Banerjee et al. (2017), which generally find that cash transfers in low and middle income countries do not reduce labor supply.

Interestingly, we observe little heterogeneity in estimated treatment effects (on assets, expenditure, income, and hours worked) among eligible households across eight pre-specified characteristics (Figure A.4), namely, respondent gender, age over 25, marital status, primary school completion, having a child in the household, an indicator for above median measured psychological well-being, and work status (in self-employment or wage employment).

The effect on net transfers received from other households is also notable: the point estimate is negative but not statistically significant, and we can reject large changes in either direction. This suggests that relatively little of the cash transfer was literally shared with neighbors or social contacts.

33. The mean for eligible households in control villages and low saturation sublocations is USD PPP 724 (with SD 863), less than the overall mean, unsurprisingly since ineligible households are wealthier.

34. As is common in low-income settings, measured values of consumption are larger than measured household income. Similarly, total measured local area income and firm revenue is lower than expenditures, in part, because measured expenditure includes important categories - including medical and schooling expenses, utilities, rent and mortgage, religious and charitable donations, and dowry, wedding and funeral costs - for which we do not typically measure corresponding revenues in the enterprise data. Expenditure measures may also better capture consumption of own-farm production than the agricultural revenue data. 
Overall, these results highlight that cash transfer recipients substantially increased their expenditure on a broad range of goods. This spending was likely financed primarily by the initial transfers themselves, with possibly some contribution from higher earnings. A large share of this spending likely takes place locally: enterprises report that 86 percent of their customers come from within the same village or sublocation. Below we therefore turn to examining impacts on local enterprises.

\subsection{Estimating the Marginal Propensity to Consume}

The marginal propensity to consume $(M P C)$ sheds light on the inter-temporal decisionmaking of households, and is an important determinant of the magnitude of a transfer multiplier, as it captures the share of income that is spent-and thus enters the hands of other agents in the economy - rather than being allocated to financial savings or retained in cash (which in our setting might include simply retaining some value on the mobile money platform). The dataset allows us to generate an intuitive estimate of the $M P C$ out of the transfer, obtained conceptually by dividing the total increase in expenditure by the size of the GiveDirectly transfer 35

Here we summarize the construction of the MPC in our data; refer to Appendix G for details. An immediate cross-sectional estimate can be obtained by dividing the effect on total household non-durable consumption in Table 1 by the size of the transfer among recipient households. However, this underestimates the $M P C$, as it is based on consumption as captured in the period preceding household survey administration, with a retrospective timeframe of at most 12 months, compared to the full transfer value, which for many households was distributed at least in part more than 12 months ago. It misses any changes to consumption occurring outside this window, particularly in early months when spending may be the highest. We can improve on this by employing the dynamic regression specification (in equation (7) ), which exploits the fact that the timing of survey data collection, relative to transfer disbursement, varied exogenously across households.

Yet this estimate is also a lower bound. As noted above, a limitation of the data collection is the relative lack of household survey data collection in the months after transfers went out, the period when, anecdotally, a large share of the transfer was spent. We thus augment the analysis by making use of data collected as part of the closely related Haushofer and Shapiro (2016) study of GiveDirectly transfers provided between 2011-2013 in a nearby part of Siaya

35. This measure is comparable to MPC estimates from tax rebates (e.g., Parker et al.|2013). Alternatively, it may be attractive to divide by the transfer size plus any additional non-transfer income generated over the period. Table 1 shows that this increase is small and not significant, with a point estimate of $\approx 7 \%$ of the transfer value. Thus results do not change substantively if this additional recipient income is included, although its inclusion does reduce the estimated MPC somewhat, see Appendix Table G.1 
County (Rarieda subcounty, lying just outside our study area), which gathered information on household consumption immediately after transfers. The $M P C$ of non-durable goods among recipients in the first three quarters following the transfer there was 0.35 (Appendix Table G.1), consistent with much spending occurring shortly after transfer receipt. Combined with estimates from our data thereafter, recipients' MPC on non-durables over the 27 months post-transfer is 0.64 . This implies that most study households receiving cash transfers were hand-to-mouth consumers, allowing us to soundly reject the permanent income hypothesis in our context.

This estimate still leaves out durable goods expenditure. First note that households report purchasing the vast majority of durables (over 95\%) in local shops. These durables may serve as consumption, savings or investment goods. A large share of such purchases in the study sample are consumer durables not primarily intended for productive uses (e.g., radios, furniture). At the same time, formal sector financial savings are limited in rural African settings like ours and much household saving comes in the form of purchases of household durable assets, which necessitates spending on local goods. Thus from the perspective of inter-temporal decision-making, durables are more of a gray area. Yet whether durables are purchased as "savings goods" or "consumption goods", both types of expenditure show up as revenue of local firms and may therefore have similar stimulus effects. Here we rely on the cross-sectional difference in the value of durable assets (including housing) between treatment and control areas among eligible households in our endline data (Table 1). Combining this non-durable expenditure yields our best estimate of the overall $M P C$ in the 27 months following transfers, at 0.93 .

Because we are interested in estimating the multiplier effect on local economic activity (within the study area), we next refine the $M P C$ estimate by focusing on spending on local value added, excluding spending on intermediates and final goods produced elsewhere. Spending on goods produced in other parts of Kenya (or the world) does not directly contribute to local GDP (although it could generate multiplier effects at larger geographic scales that we cannot readily assess with our data). We thus derive a bound on the share of spending on local value added. This is closely related to the local degree of openness that features prominently in discussions such as Farhi and Werning (2016). We find that most consumption is in fact of locally produced goods, in line with the well-known fact that a large share of household consumption in rural areas consists of locally produced food and other basic necessities (Deaton 2018). In particular, the enterprise data allows us to bound the share of imported intermediate goods sold in the study area, where, recall, over $95 \%$ of household shopping occurs ${ }^{36}$ This conservative methodology yields an upper bound of $18 \%$ for the

36. As discussed in Appendix H.1, we determine that at most a fraction $1-\frac{\text { cost }_{i}+\text { profit }_{i}}{\text { revenue }_{i}}$ of the revenue of 
expenditure-weighted share of local non-durable expenditure (and 20\% for durables) that may reflect expenditure on imported intermediates, indicating that four fifths of spending is on local value added, and thus that the study area's economy is largely closed ${ }^{37}$

Combining estimated import shares with our preferred $M P C$ estimate yields a marginal propensity to consume on local value added, which we denote $M P C_{\text {Local }}$, of approximately 0.76 in this context. Of course, this figure is subject to the data and measurement caveats noted above, as well as assumptions on the share of imports, and so should be seen as speculative. Nonetheless, taking this value of 0.76 to a basic static Keynesian model, the transfer multiplier effect on local output would be $\frac{M P C_{\text {Local }}}{1-M P C_{\text {Local }}} \approx 3.2$. We dynamically estimate the multiplier using all household, enterprise and price data in section 5 below.

\subsection{Enterprise effects}

There are large increases in revenue for enterprises in both treatment and control villages (Table 3, Panel A). Revenues in treated villages increased by USD PPP 357 per household, a $47 \%$ increase, while those in control villages increased by USD PPP 244 (32\%). Revenue gains are concentrated in the retail and manufacturing sectors: both treatment and control villages experience statistically significant increases in manufacturing revenue of similar magnitudes - USD PPP 109 and 110, respectively - while treatment villages see larger gains in retail revenue (USD PPP 141 versus USD PPP 65, Appendix Table A.2).

Estimated effects on profits are positive, but moderate in magnitude and not significantly different from zero. In fact, profit margins (measured as the ratio of profit to revenues) fell (Table 3, Panel A, Row 5). We also see no evidence of firm entry, as one might have expected if enterprises were becoming more profitable (Panel C). Overall, the data indicate that higher revenues were largely absorbed by increased payments to various factors of production. While we do not observe all of these payments, we do see significant increases in the factors that we directly measure, and particularly the wage bill: enterprises in treated (control) villages increase spending on labor by USD PPP 82 (71), a sizable change relative to the mean.

Strikingly, we do not see strong evidence of a firm investment response. Estimated increases in fixed capital investment are small, and we can reject large changes (Panel B,

firm $i$ is spent on intermediate goods; for each firm type, we then generate a revenue-weighted average upper bound for the share of intermediates in its production function. Next, we make assumptions about what share of intermediate goods is likely imported, conservatively erring on the side of assuming a high share; for instance, we assume that all intermediate goods at clothing stores (which spend up to $38 \%$ of revenue on intermediate goods) are imported, which is likely to be an upper bound.

37. In principle this exercise also depends on migration: money spent elsewhere by migrants appears in our data (as we tracked and surveyed them) but does not contribute towards the share spent on local value added. In practice household migration was uncommon, with $5 \%$ of control low-saturation household migrating, and unaffected by treatment (Table A.9, Row 1). Estimated treatment effects among non-migrants are also essentially identical to overall average effects (Table A.9, Panel 2). 
Row 2). We do see a modest increase of USD PPP 35 in inventories for enterprises located in treated villages, yet even this appears to be less than proportional to the increase in firm sales; in other words, these enterprises are, if anything, operating leaner business models (Panel B, Row 1). This pattern of results suggests that the expansion in enterprise activity is driven more by the shock to local aggregate demand than by a relaxation of credit constraints that had previously limited investment.

One caveat to this point is that some household assets are difficult to categorize into "productive" assets as opposed to consumer durables. For example, bicycles may be used for personal transportation (i.e., to visit friends), but could also be used as a bicycle taxi to generate income. We therefore inclusively categorize as "potentially productive" both livestock as well as a number of non-agricultural assets that could potentially be used for income-generating activities (beyond simply renting out the asset) 38 When we do so, overall roughly half of the increase in household asset ownership documented above is in what we believe to be purely non-productive assets, with small gains in productive agricultural assets (e.g., farm tools) and a modest gain for potentially productive assets (Table A.1). We also fail to detect any investment response for non-agricultural enterprises owned by recipient households: neither investment nor inventories increase relative to eligible owners in control villages (Table A.3, Panel B). Taken together, these patterns are also consistent with the cash transfer program generating only a limited local investment response.

\subsection{Non-recipient household effects}

There are positive and significant expenditure effects for non-recipient households. Column 3 of Table 1, Panel A presents results based on Equation (3). Notably, the magnitude of these gains (USD PPP 334, p-value < 0.01) are quite similar to those of recipient households (USD PPP 338). The pattern of expenditure increases is also broadly similar to that for recipient households, except that spending on durables does not increase among non-recipient households. One possible reason for the similarity in overall spending impacts is that the timing of effects on recipient and non-recipient households may be different, with recipient households showing impacts earlier than non-recipient households, but effects converging by roughly one year after the final transfer was received. A further potential mechanism is that labor earnings increase differentially: among non-recipients, annual labor income increases by USD 229, while the figure is USD 134 for recipients. For wage earnings, the figures are USD 183 and USD 73, respectively. Thus, the similar impacts on expenditure among recipient and

\footnotetext{
38. Potentially productive non-agricultural assets include bicycles, motorcycles, cars, boats, kerosene stoves, sewing machines, electric irons, computers, mobile phones, car batteries, solar panels or systems, and generators. Examples of residual non-productive assets include radio/CD players, kerosene lanterns, beds, mattresses, bednets, tables, sofas, chairs, cupboards, clocks, televisions, and iron sheets.
} 
non-recipient households may partly be explained by a lower labor income response among the former. Finally, note that non-recipient households include both eligibles and ineligibles, and, as shown in Table A.8, most of the gains accrue to ineligibles. These comparatively wealthier households might be gaining more from business and additional labor income, and may be imperfectly substitutable with eligibles in the labor market. As a result, they may experience a larger increase in wages than recipient and non-recipient eligibles.

How did non-recipients fund these consumption gains? One possibility is that they are dis-saving, perhaps due to social pressure to "keep up with the Joneses", their neighbors who received the transfer. However, this does not appear to be the case: estimated treatment estimates for total assets, housing and land values are all positive, although not all are significant (Table 1, Panel B). Nor do we observe a borrowing response for non-recipient households from either formal and informal sources (Table 2, Panel C, column 3). A second potential explanation is that expenditure gains reflect inter-household transfers to non-recipient households, as documented in Angelucci and De Giorgi (2009) for Mexico. This also does not seem to be the case, as we find no significant increase in net transfers received by non-recipient households, and the point estimate of USD PPP 8.75 is less than 3 percent of the expenditure gain for non-recipient households; this mirrors the lack of an effect on net transfers among recipient households noted earlier.

Rather, the data suggest that consumption gains are driven by higher earned income: total annualized income increases by USD PPP 229. It is often argued in development economics that survey estimates of consumption are better measured and often substantially larger than estimates of income, particularly for poor households (Deaton 2018). While this is true in our case, we cannot reject that the total effect on income is the same as the effect on consumption expenditure for non-recipient households $(\mathrm{p}=0.23)$. Income gains come largely from wage earnings, which increase by USD PPP 183, with a smaller and not significant contribution from profits from owned enterprises. These results are broadly in line with the enterprise results, in which profit increases were modest and marginally significant while the wage bill expanded significantly, by 68 and $58 \%$ in treatment and control villages, respectively (Table 3, row 4). Higher wage earnings appear more likely to reflect higher wages than increased labor supply, as the point estimate for overall household labor supply is actually somewhat negative (although there does appear to be an increase in respondent hours worked for wages, Table A.4). Hourly wages earned by non-recipient household increase meaningfully, although the estimate is only marginally significant (Table 2, Panel A).

To sum up the results so far, cash transfer recipient households receive and spend most of the transfer, leading to higher local enterprise revenues. This positive aggregate demand shock, in turn, appears to increase the income of local non-recipient households, leading to 
higher spending on their part. This pattern provides initial evidence for a positive multiplier effect of the cash transfer program, an issue we return to below.

\subsection{Effects on output prices}

We turn next to effects on consumer goods prices in order to understand the extent to which other monetary impacts are real as opposed to nominal. Overall, we find small, positive and precisely estimated effects on consumer goods prices. For our overall expenditure-weighed log-index of market prices both the ATE and average maximum transfer effect are small and precisely estimated near zero (Table 4). The tight standard errors allow us to rule out even relatively small price effects: with 95 percent confidence, the ATE across the study period is below 0.0022 log points, or 0.22 percent. For the average maximum transfer effect across markets, the upper bound of the 95 percent confidence interval is 0.01 log points, or 1 percent. Price effects are also small across almost all product categories. In particular, food prices are in line with the overall price index, and durable prices do not increase meaningfully. To help mitigate concerns that results may be sensitive to the price index weights or product classification, we find that average price inflation is below $1.2 \%$ for every product (Figure A.6; for alternative specifications and product classifications, see Appendix E.2).

Variation in price responses is generally in line with theoretical predictions. We observe somewhat larger price increases in markets less integrated into the local economy. Columns 3 and 4 split markets into those above and below median market access, with estimated effects typically more positive in more remote markets. Figure A.5 further breaks this pattern down by quartile of market access, with lower values reflecting more isolated markets. Panels A-C show a small amount of inflation for less tradable goods only in the most isolated markets, and smaller and less precisely estimated effects for more tradable goods, with less of a clear pattern across market access quartiles. Inflation for less tradable goods in isolated markets nonetheless remains limited, at $0.2-0.3 \%$ on average. We also carried out enterprise phone surveys of a subset of enterprise types during the period in which transfers were going out, which collected price data on a limited number of products; inflation for these local manufacturing and services prices is also limited (see Appendix E.3).

These patterns are qualitatively similar to findings in Cunha, De Giorgi, and Jayachandran (2018), who study the price effects of an in-kind food and cash transfer program in Mexico (where the household income shock was similar in magnitude to the Kenya program we study): in-kind transfers there lead to price decreases, while cash transfers lead to price increases, but their estimated effects are small except in remote villages. Filmer et al. (2018) estimate inflation of 5 to $7 \%$ for protein-rich foods in the Philippines, with smaller effect for other product categories. Burke, Bergquist, and Miguel (2019) show that a credit inter- 
vention impacting the supply of staples also affects local grain market prices in a different Kenyan region. Reconciling these results with ours is a task for future research.

\subsection{Effects on input prices}

We next examine effects on the prices of major factors of production: labor, land and capital. Table 2 presents estimated effects on these prices measured in the household survey data. We find some evidence of higher wages. In row 1 of Table 2, we examine wages for employees using household survey data. 39 In the reduced form specification, eligible households in treatment villages earn USD PPP 0.11 more per hour, on a base of USD PPP 0.70. This effect is no longer significant, however, when we also estimate across-village spillovers. For non-recipient households, the increase is even more marked at 0.19 USD PPP per hour, and significant at the $10 \%$ level. These potentially large wage effects do not seem to be driven by large labor supply responses. In row 2, we calculate the total hours worked by adult household members in agriculture, self-employment and employment, and estimate effects at the household level. Effects are relatively small and not significant. Together with the fact that enterprise wage bills increased, these patterns are strongly suggestive of positive local wage effects (Table 3). This in turn suggests that labor markets in this area are fairly localized, at least over the time horizon we study, which is consistent with the fact that we see little evidence of impacts on measures of migration (Table A.9). In the longer run, labor may become more mobile, helping to equilibrate any induced wage differentials.

Effects on estimated land prices are positive and economically meaningful (at 9-14\%), but not significant (Table 2, Panel B). Since our measure of land prices is a somewhat noisy one - formal sales are rare so we use respondents' self-reports of the amount per acre land like theirs in the same village would sell for-we also examine land rental prices as a robustness check, which yields data on actual land transactions for a subset of respondents. We do not find significant effects on land rental prices (Table A.5). Unsurprisingly, given land should be in relatively fixed supply in the short-run, we find little change in total landholdings among recipient households or those in more heavily treated areas. We also find no effects on total land rentals, nor on the total amount of land used for agriculture (Table A.5).

We estimate fairly precise null effects on interest rates and total borrowing (Table 2 , Panel C), where we measure household borrowing from both formal (e.g., banks, mobile credit services) and informal (moneylenders, family and friends) sources. The loan amount reports total borrowing across sources in the last 12 months, setting those who did not borrow equal to zero. Note that the loan-weighted interest rate is the monthly interest rate

39. We include all household members that report working for wages, and calculate their hourly wage based on hours worked in the last 7 days and their monthly salary (adjusted to weekly scale). 
on the most recent loan by source, weighted by the total amount of borrowing (by source); we include informal loans without interest, which brings down the average rate.

\section{The transfer multiplier}

We next examine what the household and enterprise responses imply for the aggregate level of economic activity, and specifically for the value of the local multiplier of cash transfers, where 'local' refers to the entire study area. We define this multiplier $\mathbb{M}$ as the cumulative effect of transfers on local real GDP, relative to the total amount $T$ transferred in real terms, over a given time interval:

$$
\mathbb{M}=\frac{1}{T}\left(\int_{t=0}^{t=\bar{t}} \Delta G D P_{t}\right)
$$

The size of the transfer multiplier is generally thought to depend in part on the policy context in which outlays are made, and in particular on the extent to which (i) monetary policy reacts, and/or (ii) households and firms expect levels of current or future taxation to change. Our setting is unusual in a useful way: because we observe a large one-time fiscal outlay that was made philanthropically, funded from outside of the economy we study, and small relative to the overall Kenyan economy, we can reasonably expect to measure a "pure" external transfer multiplier that should be independent of such effects. This feature generates estimates that can be thought of as a model primitive, and with which estimates from other financing scenarios can be contrasted.

As noted in Section 4.2, an initial calculation of the transfer multiplier as $\frac{M P C_{\text {Local }}}{1-M P C_{\text {Local }}}$ suggests that it may be substantial, at around 3.2. In this section, we refine this estimate by both accounting as fully as possible for effects on all components of GDP, including spillover effects, and accounting for dynamics. To get at real values, we deflate all monetary outcomes and transfer values to January 2015, linking the overall monthly market price index in the nearest market to each observation (Appendix H presents a nominal version).

Following national accounts definitions, the expenditure-based measure of local GDP is $G D P_{t}=C_{t}+I_{t}+G_{t}+N X_{t}$, where $C_{t}$ is consumption expenditure on non-durables and durables, measured as quarterly consumption plus accumulated assets and housing stock at endline 40 To avoid potential double-counting, we exclude expenditure on home durables, home improvements and maintenance from the consumption expenditure measure as part of this expenditure may be reflected in an accumulation of assets. In addition, we exclude net lending as well as land values from the asset measure because changes in land values

40. Note that by measuring impacts on asset stocks we (correctly) do not count transfers of existing assets between local agents as GDP, since these increase one agent's balance sheet while decreasing another's. Such transactions only introduce bias if they involve a non-local counterparty, as discussed below. 
may not be driven purely by investment, and because we think of land supply as being essentially fixed. We exclude local government expenditure, $G_{t}$, as Walker (2018) shows that the intervention had a precisely estimated null effect on it.

Since we also measure household and enterprise income, we can construct a dual incomebased measure of local GDP as the sum of factor payments and profits: $G D P_{t}=W_{t}+R_{t}+$ $\Pi_{t}+\operatorname{Tax}_{t}-N F I_{t}$, where $W_{t}$ is the total household wage bill, $R_{t}$ are rental expenses of local enterprises (assuming those are paid to capital owners within our study area), $\Pi_{t}$ are enterprise profits, and $\operatorname{Tax}_{t}$ is total enterprise taxes. ${ }^{41}$

For flow variables, we follow Section 3.8 to generate IRFs, which we integrate over time. For two components of GDP, we are instead able to measure impacts on the integral of flows over time by simply measuring impacts on accumulated stocks, simplifying the problem. Specifically, we measure effects on durable consumption expenditure using effects on the stock of endline household durable goods and the value of respondents' home, and effects on inventory investment using effects on current inventory stocks at endline. One drawback is that these figures are likely to under-estimate cumulative spending to the extent that some assets depreciated between the time of purchase and measurement, although over the limited timeframe considered this may be a second-order concern; any such bias would tend to reduce the estimated multiplier. In the graphical presentation, we assume that any effects on these stocks occurred equally across all post-treatment quarters.

Overall, we view the expenditure- and income-based multipliers as two distinct measures of the same underlying concept, each with its own limitations. Reflecting this, below we estimate them jointly and test individual as well as joint hypotheses across the two measures. We discuss limitations and robustness in detail in Section 5.2, including adjustments to account for the fact that we do not directly observe $N X_{t}$ or $N F I_{t}$.

\subsection{Multiplier estimates}

We estimate a sizeable multiplier using both main approaches, in line with the back-ofenvelope figure derived above. The estimated expenditure multiplier is 2.53 (Table 5, Panel A). $46 \%$ of this effect is driven by consumption expenditures. Household asset purchases and enterprise investment make up another $32 \%$ and 19\% respectively, and enterprise inventories are not quantitatively important. While part of the asset response could potentially reflect productive investments by household-operated enterprises, at least $43 \%$ of the asset response

41. We employ the household rather than enterprise wage bill, as the household survey sample is larger and includes individual-level wage earnings data. We omit land rental income because we do not see any significant evidence of effects on this above. In principle, a third approach to estimating GDP would be to aggregate value added from local enterprises; we do not implement this as we did not collect sufficiently comprehensive data on enterprise expenditures on intermediate inputs. 
comes from non-productive assets, across both recipient and non-recipient households (see Table A.1). Taking this into account, consumption alone leads to an estimated multiplier of at least 1.5, underscoring the overall point that cash transfers appear to have led to a predominantly demand-side driven increase in local economic activity.

The estimated income-based multiplier is quite similar in magnitude to the expenditurebased multiplier, at 2.28 (Panel B), and we cannot reject that they are the same $(p=0.88)$. This is notable since it is calculated using a completely distinct set of component measures. Of this total effect, we find that $64 \%$ reflects increased enterprise profits, $30 \%$ increased wages, and a much smaller contribution comes from capital income and taxes taken together. As noted above, the increase in consumption, and the smaller increase in investment, is therefore primarily accounted for by higher profits and wages. Of course, in our context of predominantly single-person firms, "profits" likely reflect some mix of true economic profit along with returns to the owner's capital and labor inputs. Regardless of the exact mix, however, this sum should be appropriate for our goal of calculating the aggregate incomebased multiplier.

When we examine the relative contributions of recipient and non-recipient households to both multipliers (as shares of the total household contribution), we find that non-recipient households account for $80 \%$ of the household contribution to the expenditure multiplier and $85 \%$ of the contribution to the income multiplier, both of which are somewhat higher than their share in the local population of $67 \%$. This suggests that analysis focusing only on recipient households may be missing sizable shares of program effects.

An advantage of this "macro-experimental" approach to estimating the multiplier is the ability to conduct statistical inference. To start, we reject the null of a negative multiplier (with a value less than zero) at the $10 \%$ level using either approach (Figure 1 and Table 5), and reject the null at $p=0.02$ when testing the joint restriction, and at $p=0.04$ when testing the average of both multipliers. Since the two measures exploit distinct data, we gain statistical power by examining both measures together. Rejecting a negative multiplier on real GDP is important, ruling out, for example, that prices adjusted immediately to increased spending, netting out any real effects. Testing the null hypothesis of a multiplier less than one has been a central goal of recent research on the fiscal multiplier, since it would imply a crowd out of private spending, but this value does not have the same interpretation for transfer multiplier estimates like ours where all spending is private. Nonetheless, rejecting a transfer multiplier value less than one constitutes a conservative test for the existence of positive output spillovers for non-recipients, holding even in the extreme case of $M P C=1.42$

42. A less conservative test of the no-spillovers hypothesis would be to test if the multiplier estimate is less than the MPC of recipients (which is strictly less than 1). Because this MPC is itself somewhat imprecisely 
Using the expenditure or income-based approach alone, the $p$-value on this test is 0.14 and 0.23 respectively. The average of the two multipliers is $2.40(S E=1.38, p=0.15)$, and the hypothesis that the multipliers are jointly less than one is rejected at the marginally significant $p=0.07$ level.

Figure 1 presents these results graphically, breaking up the aggregate multipliers into quarters after transfers went out. Panel A presents the expenditure-based multiplier. The increase in GDP is fairly stable over time; in fact, we cannot reject that the expenditure response is constant across all quarters (p-value of 0.73 ). It increases slightly up to a peak after 9 months (when the second lump-sum transfer has been received), and then slowly declines. Interestingly, we reject a null effect as late as two years after the transfer, suggesting that the true multiplier (out to an infinite time horizon) could be larger still and that our estimates are likely to be lower bounds. The less precisely estimated effects (with larger confidence intervals) during the first three quarters afters transfers go out are visually apparent. The income multiplier, on the other hand, visually appears to fluctuate more over time (Panel B): it is marked by a strong early response in profits, while wages appear to

take longer to rise. Yet as with the expenditure measure, we cannot reject equality of all quarterly coefficients (p-value of 0.76 ).

These estimates are somewhat larger than the higher end of recent fiscal multiplier estimates in the context of public spending in the United States (Chodorow-Reich 2019; Nakamura and Steinsson 2014), where they tend to range from 1.5 to 2.0. As noted above, the magnitudes of transfer versus fiscal spending multipliers are not directly comparable. The differences between our results and existing estimates may also reflect the relative levels of economic development and other structural differences between the Kenyan and US economies (such as the degree of openness of local economies, the share of hand-to-mouth consumers and the existence of financial savings opportunities), differences in data and measurement, as well as any effects on (or expectations of effects on) either monetary policy or future taxes in the US, the latter being response effects that this study's experimental design usefully allows us to avoid.

\subsection{Alternative assumptions}

We also consider several alternative multiplier estimates that treat prices, exports/imports, and the first three quarters of data post-transfer in different ways. A first alternative presents the multiplier in nominal rather than real terms: the nominal expenditure (income) multiplier is 2.66 (2.55), see Appendix Table H.6. Given our quantitatively small price effects, the estimated in our data (see section 4.2 , this approach does not necessarily increase power. 
differences between these and the real estimates presented in Table 5 are mainly due to the moderate degree of overall price inflation during the study period.

The expenditure- and income-based measures of GDP we generate are based on unusually rich underlying data, but each has potential limitations. In particular, each may misattribute transactions between agents located in the study area and counterparties located outside. In the expenditure case, the main concern is that we do not directly observe net exports $\left(N X_{t}\right)$. Imports show up as expenditure but are not local GDP, while exports do not show up in expenditure but are part of local GDP. To the extent that cash transfers decrease (increase) net exports from the study area, our expenditure multiplier would overstate (understate) the multiplier. Intuitively, we might expect net exports to fall following a large external income transfer: since many local firms are retail establishments, imports of intermediate goods (including packaged consumer goods ready for sale) would likely increase. This suggests that the expenditure-based approach might be upwardly biased ${ }^{43}$ Note that transactions between agents within our study area are correctly accounted for: for example, if study village A imports goods from study village B then the value of these goods should be included in local GDP as they are produced within our study area. Of course, increases in net imports could in part reflect increases in economic activity outside of the study area due to the cash transfers, which our concept of the local multiplier does not capture but which are a part of the broader impact of the intervention.

As a robustness check to gauge the magnitude of the potential bias in the expenditurebased measure due to imports of intermediate inputs, we first assign each component in the non-durable and durable expenditure measures to enterprise types at which the good is most likely to be purchased (using revenue shares of different enterprise types, where appropriate). As noted in Section 4.2, this conservative methodology yields an upper bound of $20 \%$ of local spending that may reflect expenditure on imported intermediate goods. If imports scale linearly with expenditure, this suggests a transfer multiplier of at least 2.01 on local expenditure alone (see Appendix H).

In the income case, potential bias could arise if there are changes in net wage income $\left(N F I_{t}\right)$ earned outside the study area, since this is not considered part of local GDP. This bias seems unlikely to be quantitatively important in our setting: $86 \%$ of all non-farm employees are family labor (and therefore presumably overwhelmingly local), and among individuals employed for a wage, only $6 \%$ report an employment contact address outside the study area.

\footnotetext{
43. Note that direct imports by households themselves are unlikely to increase because on average only $10 \%$ of households report ever shopping at a market outside our study area, and overall the impacts we see on household spending and local enterprise revenue are fairly similar, suggesting that consumer spending was quite localized. Similarly, non-farm businesses report only $5 \%$ of customers coming from outside the study area, and that share does not change significantly in response to treatment.
} 
To the extent some bias remains, we would expect it to be negative (towards zero), if net labor income earned outside the study area decreases in response to higher local business revenue, employment and wages. This suggests that the income-based approach may yield a lower bound on the multiplier. Consistent with this bounding logic, the estimated income multiplier is somewhat smaller in magnitude than the expenditure multiplier.

Next, we examine how alternative estimates of effects over the first three quarters affect the overall multiplier estimate. A conservative approach excludes effects on GDP during the first three quarters after transfers arrive, which may be statistically attractive in a mean squared error sense since it yields more precise, if surely somewhat downward biased, estimates. Under this assumption, the expenditure (income) multiplier estimate is 2.04 (1.45), which is smaller than the preferred estimates in Table 5, as expected, and estimates attain greater statistical significance (see Appendix Table H.4). An arguably more realistic method utilizes the household consumption data from Haushofer and Shapiro (2016) for the first three quarters post-transfer, as we did in the construction of the MPC discussed above. This yields a larger estimated expenditure multiplier of 3.09, with the increase due to a greater contribution from recipients' non-durable consumption (see Appendix Table H.4). When this refinement is combined with our preferred assumptions on input shares, the expenditure multiplier estimate is 2.48 (Appendix Table H.5). Though it relies on additional assumptions, some readers may prefer this estimate since it addresses several limitations in measurement of the main expenditure multiplier estimate.

\section{Welfare implications}

Transfer multiplier estimates have typically been used for positive economic analysis, to predict how fiscal policy will affect output. Yet since output is not social welfare, how fiscal policy affects welfare is a distinct issue. Classic derivations of fiscal multipliers from accounting relationships such as the "Keynesian cross" could not deliver parallel statements about welfare as they were not grounded in models of individual preferences. While recent papers have focused primarily on estimation (Ramey 2019), a few have examined the relationship between fiscal multipliers and welfare in the context of micro-founded models, emphasizing that multipliers need not be sufficient statistics for welfare or (consequently) for optimal policy (Sims and Wolff 2018). In fact, Mankiw and Weinzierl (2011) construct examples in which the interventions with the largest multipliers have the least impact on social welfare. The program evaluation literature on cash transfers, meanwhile, has largely focused on estimating behavioral responses without exploring what these mean for welfare.

Here we examine the broad channels through which transfers could affect household 
welfare, and how these relate to the transfer multiplier. Let indirect utility function $v_{i}\left(T_{i}, T\right)$ define the utility achieved by household $i$ when it receives a (possibly zero) transfer $T_{i}$ while other eligible households in the area receive transfers of $T$ each. We are interested in characterizing how $T$ affects the quantity $T_{i}^{*}$ defined by $v_{i}\left(T_{i}^{*}, 0\right)=v_{i}\left(T_{i}, T\right)$, in other words, the transfer that would make household $i$ indifferent between receiving $T_{i}^{*}$ on the one hand, and experiencing the intervention we study on the other. Notice that if there were no general equilibrium effects, in the sense that $v_{i}$ did not depend on $T$, then we would simply have $T_{i}^{*}=T_{i}$, i.e., the tautology that the value of receiving a dollar is a dollar.

We think of $v_{i}$ as the value of some generic underlying optimization problem

$$
v_{i}\left(T_{i}, T\right)=\max _{x_{i}} u_{i}\left(x_{i}, x_{-i}(T)\right) \text { s.t. } x_{i} \in X\left(T_{i}, T\right)
$$

Here $u_{i}$ represents preferences over variables $x_{i}$ which the household chooses from a set $X$, as well as variables $x_{-i}$ chosen by others. This formulation delineates two ways in which $T$ can affect the utility of household $i$. First, it may change market outcomes that determine the choice set $X$ - for example, prices or income from various sources. We therefore need to interpret the impacts on output that generate the transfer multiplier through this lens. Second, it may change behaviors $x_{-i}(T)$ that affect $i$ 's well-being without appearing in the transfer multiplier (e.g., through externalities).

\subsection{Market outcomes}

An increase in (real) output must reflect some combination of (i) an increase in the employment of factors of production and (ii) an increase in their aggregate productivity. While the latter represents an unambiguous welfare gain, the former comes at an opportunity cost the value of foregone leisure, for example, in the case of labor inputs, or of foregone present consumption in the case of capital inputs. Appendix J provides a formal illustration of the mapping from household welfare to aggregate output, emphasizing this point. The discussion also illustrates how household welfare differs from household expenditure, which is often used in the program evaluation literature as a proxy for well-being. Specifically, expenditure does not take into account the opportunity cost of supplying labor (or other inputs), and over any finite time interval incorrectly interprets dis-saving as a welfare gain.

A key question is thus the extent to which the output response we observe can be explained by increases in the supply of scarce factors of production. In the data, we find fairly limited evidence of increases in the employment of either land, labor, or capital. Land is in relatively fixed supply; agricultural households do not report owning or renting more of it (Table A.5) and we would not expect it to be a limiting factor in the sectors in which 
the output expansion is concentrated (namely, retail and manufacturing). Total household labor supply does not change significantly (Table 2), though we do see a net shift out of self-employment and into wage employment (Table A.4, Panel A), with the latter increasing by 1.8 hours per person per week on average across recipients and non-recipients. These estimates are not statistically different from zero, however, and even under generous assumptions can explain only around a 5\% increase in real output, well below the observed response. ${ }^{44}$

As for capital, the non-agricultural enterprises that increased their output did not increase investment in fixed capital (Table 3, row 7) and, while increasing inventories somewhat, actually decreased them slightly in proportion to sales (Table 3 , row 6). Moreover, if investment were driving output increases then we would expect to see these increases concentrated in enterprises owned by recipients, who gained access to a new source of capital, but if anything we find the opposite (Table A.3). Overall, the limited factor supply response suggests that the bulk of the output response we estimate must be attributable to productivity gains, and should thus be valued at roughly $\$ 1$ per $\$ 1$ in welfare terms. (We discuss productivity further in Section 7.)

The distribution of benefits also matters for welfare to the extent we value more highly expansions in the budget sets of poorer households. While transfers were targeted to relatively poor households, we have seen that large spillovers accrued to their somewhat richer neighbors. Indeed, we find no significant reductions in village-level Gini coefficients for consumption expenditure or wealth in treatment villages, and a small and marginally significant $(p<0.1)$ increase for wealth in control villages (Table A.7). We also reject in most cases the null that observed effects on Gini coefficients are equal to the counterfactual changes we might have expected had there been no spillovers. Overall, the patterns underscore the large spillover gains for non-recipient households: wealthier non-recipients benefit along with recipients, on some dimensions so much that inequality may slightly increase.

Distributional effects could also work through prices; while the overall price level changed only slightly, changes in relative prices could transfer value between net buyers and net sellers of goods and services. However, as for the overall index, effects are muted across all individual goods prices that we measured, with nearly all changes within a $-1 \%$ to $+1 \%$ range, indicating that any redistributive effects via price changes are likely to be very small (Figure A.6).

44. Specifically, an increase of 1.8 hours per person is a $7.7 \%$ increase in wage labor hours. Assuming a Cobb-Douglas production function with a labor share of $2 / 3$, and no productive value of time given up from self-employment, this implies a $5.2 \%$ increase in real output. 


\subsection{Non-market outcomes and externalities}

We measured several outcomes that do not enter into our multiplier calculation but that arguably influence well-being or proxy for it, and may thus capture externalities either between or within households $\left(x_{-i}(T)\right.$ in Equation 9). Specifically, we examine indices for psychological well-being, health status, food security, education, female empowerment, and security from crime. Each index is the inverse-covariance-weighted sum of component $z$-scores signed so that positive values indicate better outcomes ${ }^{45}$ The index for psychological well-being can be interpreted as a measure of overall well-being. The next four indices arguably capture intra-household externalities, while security from crime is an inter-household externality.

For recipient households, we find positive and significant reduced-form effects for four of the six indices: psychological well-being, food security, education and security. Estimates are close to zero and not significant for health and female empowerment ${ }_{46}^{46}$ Total effects including spillovers are similar for all but the security index. For non-recipient households, on the other hand, we find no significant effects except for a 0.1 SD increase in the education index $(p<0.10)$. We do not find evidence of adverse spillover effects for non-recipient households on any index, with point estimates positive for all but the security index, which is indistinguishable from zero (-0.02 SD, SE 0.07). Village public good provision was also unchanged (Walker 2018).

Overall, this pattern of findings suggests that the most important welfare effects were market-mediated, though of course there may be other external effects we did not measure. A possible exception is the impacts on inequality noted above: to the extent that households care about comparisons with neighbors, these may constitute a form of "psychic externality."

\section{Discussion: utilization of productive capacity}

The results raise the question of which features of the local economy enabled it to respond elastically to a large aggregate demand shock. While fully addressing this is beyond the scope of the present project, we outline what can be said given available data.

Any explanation of these patterns must apply to the retail and manufacturing sectors specifically, as it is here rather than in agriculture or services that output gains are concentrated (Table A.2). Moreover, it cannot rely on an increase in the employment of factors of production, since we find little evidence of this (Section 6.1). It must instead reflect an

45. The first five of these were pre-specified as primary outcomes; the components of the security index were pre-specified as part of a family of outcomes, though combining them into an index was not. Details on index construction and results for components are in Appendix A, and PAP details in Appendix I.

46. The latter (non)-result contrasts with Haushofer and Shapiro (2016) who found increases in female empowerment and reductions in domestic violence among households receiving a similar transfer. 
increase in the utilization of factors employed, as well as in the throughput of intermediate goods. This notion is consistent with our observation (during fieldwork) of the retail and manufacturing enterprises in the area, which typically involve some degree of "on-demand" production. A retail establishment, for example, requires premises and an employee to "mind the shop," but once these are in place the volume of goods it sells depends largely on consumer demand. Similarly, many small-scale manufacturing enterprises require equipment and staff to be in place but then produce only when customers arrive. In fact, about $60 \%$ of manufacturing revenue accrues to just two enterprise types, grain mills and welding shops, both of which largely operate in this way.

These examples suggest retail and manufacturing sectors in which there are important inputs whose costs are fixed over the relevant ranges - e.g., a building, milling machinery, or hiring an employee - and whose utilization thus depends on demand. While we did not measure capacity utilization directly, some indirect evidence suggests the existence of meaningful slack. The average non-agricultural enterprise saw just 1.9 customers per hour, in between which other inputs (i.e., employee time, fixed capital, inventories, etc.) may sit idle. For labor inputs in particular, $72 \%$ of non-agricultural enterprises have just a single employee, which suggests that (due to integer constraints) the labor input is essentially fixed over the relevant range. ${ }^{47}$

Given this structure of production, we would expect the revenue from additional sales to be paid out to the suppliers of intermediate goods, the suppliers of elastic factors of production (whose marginal product increased as they became better utilized), and to enterprise owners to the extent they can extract economic profits. We do not directly measure purchases of intermediates, but upper bounds for the expenditure-weighted share of intermediate inputs in total sales are sizeable, at $58 \%$ in the retail and $18 \%$ in the manufacturing sector (see Appendix H). We also see an increase in wage bills, which accounts for $26 \%$ of increased revenue (Table 3). Estimated effects on profits, meanwhile, are positive but modest and not statistically significant (and may in any case be better interpreted as returns to the owners' capital or labor which, as usual, are difficult to distinguish from true economic profits).

While suggestive, this interpretation of the supply side response to a demand shock is consistent with other recent findings. In Uganda, Bassi et al. (2019) find that employees in on-demand manufacturing (e.g., welding, furniture-making) spend about $25 \%$ of time "waiting for customers" or "eating and resting." More broadly, it relates to the old idea in development economics that it might be possible to expand production without notable

47. Note that while we do not observe a large response in reported labor supply, we are not measuring utilization of labor capacity at the intensive margin; e.g., we do not distinguish between the time a shopkeeper waits for customers or serves them. 
price inflation due to the availability of slack capacity. Classic arguments focused on "surplus labor" due to artificially high wages (Lewis 1954), while here both labor and capital appear to have been underutilized due to limited flexibility to scale their employment to match demand. Local mechanisms to address this through better coordination, such as periodic markets, do so imperfectly, leaving some degree of residual excess capacity 48

A deeper question is whether specific market failures contribute to slack capacity in steady-state in rural Kenya. Here we speculate about possibilities and directions worthy of future investigation. The most immediate explanation revolves around the small scale of local market activity; for instance, a single grain mill typically serves each village. While the capacity provided by the standard grinding machine and the worker staffing it may generate positive profit for the owner, this capacity may also exceed average local demand, implying excess steady-state capacity which could be engaged following a demand shock. The small scale of local markets is itself likely to reflect the poor road quality and high transport costs that characterize rural Africa (Foster and Briceno-Garmendia 2010). The same logic suggests that multipliers could be smaller in cities due to their greater population density and better transportation infrastructure, not to mention the fact that rural economies are often relatively closed, with large shares of consumption coming in the form of locally produced food and other basic necessities.

Contracting frictions and institutions may also affect local market structure and capacity. For instance, Bassi et al. (2019) document a pattern of small industrial clusters in neighboring Uganda, in which a dozen small carpentry firms producing nearly identical products may co-exist in the same area. Each of these separately owned firms has one or at most a few employees, and they are characterized by the slack labor capacity noted above. Consolidation into fewer, larger firms - each better utilizing workers' time and any installed machinery, and run by a more capable manager - could conceivably reduce slack and free up labor to shift to alternate activities. Further research on the legal, financial and output market frictions that prevent horizontal integration of this kind would be useful 49

\section{Conclusion}

A large-scale cash transfer program in rural Kenya led to sharp increases in the consumption expenditures of recipient households, and extensive broader effects on the local economy, including large revenue gains for local firms (that line up in magnitude with household con-

48. A growing literature also finds evidence of excess capacity in rich countries, especially in periods of recession (Murphy 2017; Michaillat and Saez 2015; Chodorow-Reich 2019).

49. Another fruitful direction for further investigation is whether cash transfers triggered a productivityenhancing re-allocation of factors of production across sectors and firms (Hsieh and Klenow 2009). 
sumption gains), as well as similar increases in consumption expenditures for non-recipient and recipient households approximately a year and a half after the initial transfers. Firms do not meaningfully increase investment, and there was minimal local price inflation, with precisely estimated effects of less than $1 \%$ on average across a wide range of goods. Two independent calculations of the local transfer multiplier using consumption data and income data yield estimates of approximately 2.4, and reject the hypothesis that the multipliers are less than or equal to 1 with $90 \%$ confidence. Several suggestive patterns are consistent with the existence of "slack" on the production side in our context, which may partially account for the large estimated multiplier.

Concerns that cash transfer programs like the one we study could have adverse consequences for non-recipients were not borne out in our setting. Firm revenues and non-recipient households' consumption expenditures rise substantially in areas receiving large cash transfers; there is little price inflation; overall economic inequality does not increase meaningfully in treated areas; nor are there negative effects in terms of domestic violence, health, education, psychological well-being, and local public goods. Instead, the positive spillovers we find suggest that RCTs of cash transfer programs that simply compare outcomes in treatment versus control villages may understate true overall impacts by ignoring the general equilibrium effects that we capture (along the lines that Miguel and Kremer (2004) argue in the context of a health program).

This study is among the first to exploit randomized controlled trial methods to directly estimate macroeconomic parameters and more broadly capture large-scale aggregate effects of a development program. The multiplier effects that we focus on here have been the subject of intense interest since at least the seminal work of Keynes (1936). Our approach thus provides a novel counter-example to the well-known critique that RCT methods are not well-suited to studying the "big" questions in development economics (Bardhan 2005; Easterly 2006; Deaton 2010). We demonstrate that there need not always be a trade-off between a study's rigor and its relevance: economics research can increasingly achieve both \begin{tabular}{|l|l|l|l|}
\hline Muralidharan and Niehaus 2017 ; Burke, Bergquist, and Miguel 2019).
\end{tabular}

The extent to which the multiplier results apply to other settings merits further discussion. They are likely particularly relevant for rural areas of low and middle income economies that share structural and institutional features with Kenya, including many other African settings. One open question is the extent to which targeting of particular types of households, and the distribution of spending propensities across households, affect the multiplier: for example, spillover effects might have been more muted if the program had also targeted transfers to some better-off households with lower marginal propensities to spend on local goods than the poor rural households we study. A second issue is how the multiplier may 
vary over the business cycle. It is noteworthy that we estimate a large multiplier during a period when the Kenyan economy was experiencing steady economic growth, rather than a recession; this suggests that any under-utilization of supply side capacity is not simply temporary or cyclical in rural Kenya, but may be more persistent 50 All that said, the results do not necessarily imply that "helicopter drops" of money as part of a scaled-up national cash transfer program would yield similar results, taking into account potential differences across rural and urban locations. The source of funding would also matter: simply printing money, for example, would likely have different inflationary consequences than financing via foreign contributions, as we study here (and is common for many social protection schemes).

Looking ahead, a traditional perspective in the case of an open economy with complete markets is that the economy should eventually revert to its previous steady-state after a local aggregate demand shock like the one we study ends, with only transient effects on consumption and prices (Farhi and Werning 2016). However, other theoretical perspectives from international trade, economic geography, and development (e.g., Marshall 1890, Rosenstein-Rodan 1943, Murphy, Shleifer, and Vishny 1989, Krugman 1991), as well as the liquidity traps literature, suggest there could be persistent local effects of a temporary cash infusion, due to agglomeration effects, increasing returns, changes in income inequality, market structure and firm specialization, and even shifts in the social networks of traders and suppliers. Temporary cash transfers and other forms of assistance have also been shown to have effects on long-run human capital accumulation and earnings (Bouguen et al. 2019; Baird et al. 2016). An evaluation of long-run patterns of economic activity, firm dynamics, migration, and household living standards in the sample communities would provide a valuable experimental test of these theories.

\section{References}

Angelucci, Manuela, and Giacomo De Giorgi. 2009. "Indirect effects of an aid program: how do cash transfers affect ineligibles' consumption?" Am. Econ. Rev. 99 (1): 486-508.

Auerbach, Alan J, Yuriy Gorodnichenko, and Daniel Murphy. 2020. "Local Fiscal Multipliers and Fiscal Spillovers in the United States." IMF Economic Review, 195-229.

Baird, Sarah, Joan Hamory Hicks, Michael Kremer, and Edward Miguel. 2016. "Worms at Work: Long-run Impacts of a Child Health Investment." QJE 131:1637-80.

Baird, Sarah, Craig McIntosh, and Berk Ozler. 2011. "Cash or Condition? Evidence from a Cash Transfer Experiment." QJE 126 (4): 1709-53.

50. Recent work argues that there may be a related phenomenon of steady-state "liquidity traps" or "secular stagnation" in advanced economies (e.g., Rachel and Summers 2019, Mian, Straub, and Suf, fforthcoming). 
Banerjee, Abhijit, Rema Hanna, Gabriel E. Kreindler, and Benjamin A. Olken. 2017. "Debunking the Stereotype of the Lazy Welfare Recipient: Evidence from Cash Transfer Programs." World Bank Research Observer 32 (2): 155-184.

Bardhan, Pranab. 2005. "Theory or Empirics in Development Economics." Economic and Political Weekly 40 (40).

Bassi, Vittorio, Raffaela Muoio, Tommaso Porzio, Ritwika Sen, and Esau Tugume. 2019. Achieving Scale Collectively. Technical report.

Bastagli, F., J. Hagen-Zanker, L. Harman, V. Barca, G. Sturge, and T. Schmidt with L. Pellerano. 2016. Cash transfers: what does the evidence say? Overseas Development Institute.

Bouguen, A., Y. Huang, M. Kremer, and E. Miguel. 2019. "Using RCTs to Estimate LongRun Impacts in Development Economics." Annual Rev. of Econ. 11:523-61.

Broda, Christian, and Jonathan A. Parker. 2014. "The Economic Stimulus Payments of 2008 and the Aggregate Demand for Consumption." J. of Monetary Econ. 68:S20-36.

Burke, Marshall, Lauren Falcao Bergquist, and E. Miguel. 2019. "Sell Low and Buy High: Arbitrage and Local Price Effects in Kenyan Markets." QJE 134 (2): 785-842.

Cameron, A.C., J.B. Gelbach, and D.L. Miller. 2008. "Bootstrap-Based Improvements for Inference with Clustered Errors." Review of Econ. and Stat. 90 (3): 414-27.

Chodorow-Reich, Gabriel. 2019. "Geographic Cross-Sectional Fiscal Spending Multipliers: What Have We Learned?" AEJ: Economic Policy 11 (2): 1-34.

Conley, Timothy G. 2008. "Spatial Econometrics." In The New Palgrave Dictionary of Economics, Second Edition, edited by Steven N. Durlauf and Lawrence E. Blume, 7:741-47. Houndsmills: Palgrave Macmillan.

Corbi, Raphael, Elias Papaioannou, and Paolo Surico. 2019. "Regional Transfer Multipliers." Review of Economic Studies 86:1901-1934.

Cunha, Jesse M, Giacomo De Giorgi, and Seema Jayachandran. 2018. "The Price Effects of Cash Versus In-Kind Transfers." Review of Economic Studies 86 (1): 240-81.

Deaton, Angus. 2010. "Instruments, Randomization, and Learning about Development." Journal of Economic Literature 48 (2): 424-55.

Deaton, Angus S. 2018. The Analysis of Household Surveys: A Microeconometric Approach to Development Policy. New York: World Bank Group.

Donaldson, Dave, and Richard Hornbeck. 2016. "Railroads and American Economic Growth: A 'Market Access' Approach." QJE 131 (2): 799-858.

Easterly, William. 2006. The White Man's Burden: Why the West's Efforts to Aid the Rest Have Done so Much Ill and so Little Good. Penguin Books.

Evans, David K., and Anna Popova. 2017. "Cash Transfers and Temptation Goods." Economic Development and Cultural Change 65 (2): 189-221.

Farhi, Emmanuel, and Ivan Werning. 2016. "Fiscal Multipliers: Liquidity Traps and Currency Unions." In Handbook of Macroeconomics, edited by J.B. Taylor and H. Uhlig, 2:2417-92. Amsterdam: Elsevier.

Filmer, Deon, Jed Friedman, Eeshani Kandpal, and Junko Onishi. 2018. "Cash Transfers, Food Prices, and Nutrition Impacts on Nonbeneficiary Children." March.

Foster, Vivien, and Cecilia Briceno-Garmendia. 2010. Africa's Infrastructure: A Time for Transformation. Washington DC: World Bank Publications. 
Haushofer, Johannes, and Jeremy Shapiro. 2016. "The Short-Term Impact of Unconditional Cash Transfers to the Poor: Experimental Evidence from Kenya." QJE 131 (4): 19732042.

Hsieh, Chang-Tai, and Peter J. Klenow. 2009. "Misallocation and Manufacturing TFP in China and India." QJE 124 (4): 1403-1448.

Keynes, John Maynard. 1936. The General Theory of Employment, Interest and Money. London: Macmillan.

Kraay, Aart. 2014. "Government Spending Multipliers in Developing Countries: Evidence from Lending by Official Creditors." AEJ: Macroeconomics 6 (4): 170-208.

Krugman, Paul. 1991. "Increasing Returns and Economic Geography." Journal of Political Economy 99 (3): 483-499.

Lewis, W. Arthur. 1954. "Economic Development with Unlimited Supplies of Labour." The Manchester School 22 (2): 139-191.

MacKinnon, James G., and Matthew D. Webb. 2018. "The wild bootstrap for few (treated) clusters." Econometrics Journal 21 (2): 114-35.

Mankiw, N. Gregory, and Matthew Weinzierl. 2011. "An Exploration of Optimal Stabilization Policy." Brookings Papers on Economic Activity 42 (1): 209-272.

Marshall, Alfred. 1890. The Principles of Economics. McMaster University.

Mian, Atif, Ludwig Straub, and Amir Sufi. Forthcoming. "Indebted Demand." QJE.

Michaillat, Pascal, and Emmanuel Saez. 2015. "Aggregate Demand, Idle Time, and Unemployment." QJE 130 (2): 507-569.

Miguel, Edward, and Michael Kremer. 2004. "Worms: identifying impacts on education and health in the presence of treatment externalities." Econometrica 72 (1): 159-217.

Muralidharan, Karthik, and Paul Niehaus. 2017. "Experimentation at Scale." Journal of Econ. Perspectives 31 (4): 103-24.

Murphy, Daniel. 2017. "Excess capacity in a fixed-cost economy." European Economic Review 91:245-60.

Murphy, Kevin M., Andrei Shleifer, and Robert W. Vishny. 1989. "Industrialization and the Big Push." Journal of Political Economy 97 (5): 1003-1026.

Nakamura, Emi, and Jón Steinsson. 2014. "Fiscal Stimulus in a Monetary Union: Evidence from US Regions." American Economic Review 104 (3): 753-92.

Parker, J.A., N.S. Souleles, D.S. Johnson, and R. McClelland. 2013. "Consumer Spending and the Economic Stimulus Payments of 2008." AER 103 (6): 2530-53.

Pennings, Steven. 2021. "Cross-Region Transfer Multipliers in a Monetary Union: Evidence from Social Security and Stimulus Payments." AER 111 (5): 1689-1719.

Rachel, Lukasz, and Lawrence H. Summers. 2019. "On falling neutral real rates, fiscal policy, and the risk of secular stagnation." Brookings Papers on Economic Activity.

Ramey, Valerie A. 2019. "Ten Years after the Financial Crisis: What Have We Learned from the Renaissance in Fiscal Research?" Journal of Econ. Perspectives 33 (2): 89-114.

Rosenstein-Rodan, Paul N. 1943. "Problems of Industrialisation of Eastern and Southeastern Europe." Economic Journal 53:202-11.

Sadoulet, E., A. de Janvry, and Benjamin Davis. 2001. "Cash Transfer Programs with Income Multipliers: PROCAMPO in Mexico." World Development (6): 1043-56.

Sims, Eric, and Jonathan Wolff. 2018. "The Output and Welfare Effects of Government Spending Shocks Over the Business Cycle." International Econ. Rev. 59 (3): 1403-35. 
Suarez Serrato, Juan Carlos, and Philippe Wingender. 2016. Estimating Local Fiscal Multipliers. Unpublished.

Thome, Karen, Mateusz Filipski, Justin Kagin, J. Edward Taylor, and Benjamin Davis. 2013. "Agricultural spillover effects of cash transfers: What does LEWIE have to say?" American Journal of Agricultural Economics 95 (5): 1338-1344.

Walker, Michael. 2018. "Informal Taxation Responses to Cash Transfers: Experimental Evidence from Kenya." July.

World Bank. 2017. Closing the Gap: The State of Social Safety Nets. Washington, D.C. 
Figure 1: Transfer multiplier over time
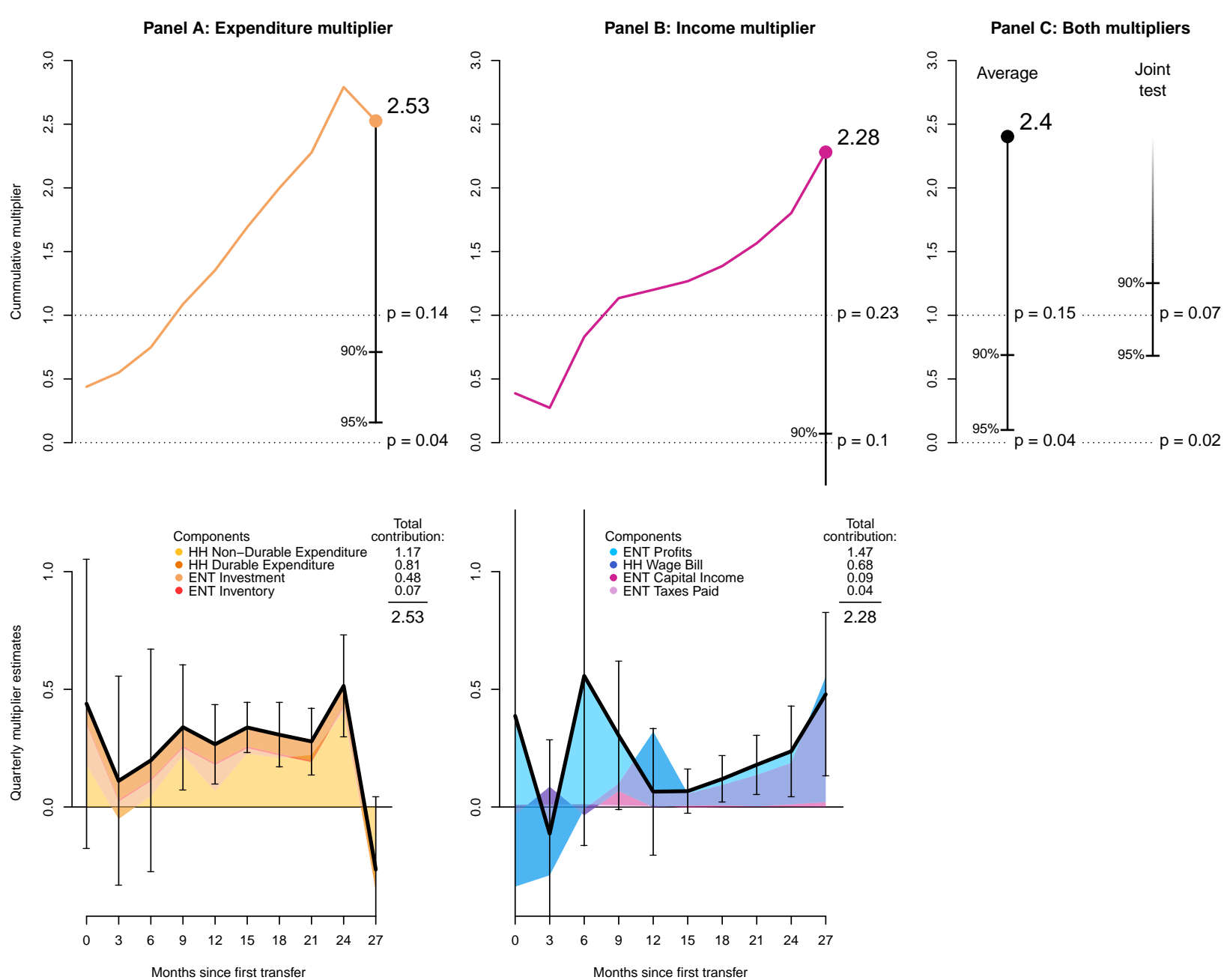

Notes: Panel A shows the cumulative expenditure multiplier over the first 29 months after start of the transfers in the top panel, and the corresponding quarterly impulse response function (IRF) in the bottom panel. The integral under this IRF yields our overall point estimate of 2.53. Colored areas below the IRF represent the different components of expenditure and the adjacent table indicates their total (over time) contribution. Darker shading indicates cases where a component turns negative in a given quarter, leading some areas to overlap. Brackets around the quarterly IRF point estimates indicate \pm 1 SE confidence intervals obtained from 2000 wild bootstrap replications. Whiskers below the overall point estimate indicate one-sided confidence intervals from the same bootstrap procedure, with $p$-values corresponding to tests of the one-sided hypotheses $H_{0}: \mathbb{M}<0$ and $H_{0}: \mathbb{M}<1$ presented at the horizontal lines at 0 and 1 respectively. Panel B repeats the same exercise for the income multiplier. Panel $\mathrm{C}$ presents results from aggregating the two estimators either by averaging them (left-hand side) or testing the joint null that both are less than the indicated critical values (right-hand side). In each case whiskers indicate one-sided confidence intervals obtained via the bootstrap as above. 


\section{Table 1: Expenditures, Savings and Income}

\begin{tabular}{|c|c|c|c|c|}
\hline & $(1)$ & $(2)$ & \multirow{3}{*}{$\begin{array}{c}(3) \\
\text { Non-recipient Households } \\
\text { Total Effect } \\
\text { IV }\end{array}$} & \multirow[b]{3}{*}{$\begin{array}{c}\text { Control, low saturation } \\
\text { mean }(\mathrm{SD})\end{array}$} \\
\hline & \multicolumn{2}{|c|}{ Recipient Households } & & \\
\hline & $\begin{array}{l}\mathbb{1} \text { (Treat village) } \\
\text { Reduced form }\end{array}$ & $\begin{array}{l}\text { Total Effect } \\
\text { IV }\end{array}$ & & \\
\hline $\begin{array}{l}\text { Panel A: Expenditure } \\
\text { Household expenditure, annualized }\end{array}$ & $\begin{array}{l}292.98^{* * *} \\
(60.09)\end{array}$ & $\begin{array}{l}338.16^{* * *} \\
(109.36)\end{array}$ & $\begin{array}{l}333.73^{* * *} \\
(123.24)\end{array}$ & $\begin{array}{c}2,536.86 \\
(1,934.09)\end{array}$ \\
\hline Non-durable expenditure, annualized & $\begin{array}{l}186.96^{* * *} \\
(58.55)\end{array}$ & $\begin{array}{l}226.74^{* *} \\
(99.62)\end{array}$ & $\begin{array}{l}316.62^{* * *} \\
(119.79)\end{array}$ & $\begin{array}{c}2,471.49 \\
(1,877.82)\end{array}$ \\
\hline Food expenditure, annualized & $\begin{array}{l}71.61^{*} \\
(36.93)\end{array}$ & $\begin{array}{l}133.55^{* *} \\
(63.98)\end{array}$ & $\begin{array}{l}132.84^{* *} \\
(58.58)\end{array}$ & $\begin{array}{c}1,578.43 \\
(1,072.31)\end{array}$ \\
\hline Temptation goods expenditure, annualized & $\begin{array}{c}6.51 \\
(5.79)\end{array}$ & $\begin{array}{c}5.88 \\
(8.82)\end{array}$ & $\begin{array}{c}-0.71 \\
(6.50)\end{array}$ & $\begin{array}{c}37.10 \\
(123.59)\end{array}$ \\
\hline Durable expenditure, annualized & $\begin{array}{l}95.18^{* * *} \\
(12.64)\end{array}$ & $\begin{array}{l}109.07^{* * *} \\
(20.23)\end{array}$ & $\begin{array}{c}8.41 \\
(12.50)\end{array}$ & $\begin{array}{c}59.44 \\
(230.90)\end{array}$ \\
\hline $\begin{array}{l}\text { Panel B: Assets } \\
\text { Assets (non-land, non-house), net borrowing }\end{array}$ & $\begin{array}{l}178.09^{* * *} \\
(24.61)\end{array}$ & $\begin{array}{l}182.01^{* * *} \\
(44.25)\end{array}$ & $\begin{array}{l}132.63^{*} \\
(78.32)\end{array}$ & $\begin{array}{c}1,132.15 \\
(1,420.22)\end{array}$ \\
\hline Housing value & $\begin{array}{l}372.78^{* * *} \\
(25.25)\end{array}$ & $\begin{array}{l}480.68^{* * *} \\
(38.88)\end{array}$ & $\begin{array}{c}72.58 \\
(215.70)\end{array}$ & $\begin{array}{c}2,033.72 \\
(5,030.37)\end{array}$ \\
\hline Land value & $\begin{array}{c}50.86 \\
(186.08)\end{array}$ & $\begin{array}{l}153.09 \\
(262.48)\end{array}$ & $\begin{array}{c}572.07 \\
(458.28)\end{array}$ & $\begin{array}{c}5,030.72 \\
(6,607.61)\end{array}$ \\
\hline $\begin{array}{l}\text { Panel C: Household balance sheet } \\
\text { Household income, annualized }\end{array}$ & $\begin{array}{r}77.62^{*} \\
(43.66)\end{array}$ & $\begin{array}{l}134.02 \\
(93.83)\end{array}$ & $\begin{array}{l}229.46^{* * *} \\
(88.59)\end{array}$ & $\begin{array}{c}1,023.45 \\
(1,634.70)\end{array}$ \\
\hline Net value of household transfers received, annualized & $\begin{array}{c}-1.68 \\
(6.81)\end{array}$ & $\begin{array}{l}-7.44 \\
(13.06)\end{array}$ & $\begin{array}{c}8.75 \\
(19.10)\end{array}$ & $\begin{array}{c}130.18 \\
(263.75)\end{array}$ \\
\hline Tax paid, annualized & $\begin{array}{c}1.95 \\
(1.28)\end{array}$ & $\begin{array}{l}-0.09 \\
(2.02)\end{array}$ & $\begin{array}{c}1.66 \\
(2.02)\end{array}$ & $\begin{array}{c}16.93 \\
(36.51)\end{array}$ \\
\hline Profits (ag \& non-ag), annualized & $\begin{array}{l}24.70 \\
(23.18)\end{array}$ & $\begin{array}{c}33.73 \\
(48.95)\end{array}$ & $\begin{array}{c}44.08 \\
(45.35)\end{array}$ & $\begin{array}{c}485.20 \\
(787.10)\end{array}$ \\
\hline Wage earnings, annualized & $\begin{array}{c}42.51 \\
(32.24)\end{array}$ & $\begin{array}{c}73.72 \\
(60.83)\end{array}$ & $\begin{array}{l}182.99^{* * *} \\
(65.44)\end{array}$ & $\begin{array}{c}495.37 \\
(1,231.56)\end{array}$ \\
\hline
\end{tabular}

Notes: Column 1 reports the coefficient on an indicator for treatment village from a regression using data from eligible households (as classified by the GE census team), and includes an indicator for saturation status of the sublocation (Equation 1). Column 2 reports the total effect on treated households (eligible recipients) from the "optimal" IV spatial regression of each outcome on the amount transferred per capita to a household's own village $v$ (instrumented by village treatment status), and to villages other than $v$ in each $2 \mathrm{~km}$ radii band around the household (instrumented by the share of eligible households assigned to treatment in villages other than $v$ inside the buffer), as in Equation 2. For this analysis, the sample is restricted to eligible households, including between 5,372 and 5,424 observations. Column 3 presents the average spillover effect on eligible households in control villages as well as ineligible households (5,448 to 5,509 observations), coming from a stacked spatial regression of each outcome on the amount transferred per capita GDP to each $2 \mathrm{~km}$ radii band around each household (instrumented by the share of eligibles assigned to treatment in each buffer), as in Equation 3. The reported average effect comes from a population-share-weighted average effect experienced by those two groups, and is representative of the average untreated household. The number of radii bands included in Columns 2 and 3 is chosen, as pre-specified, by minimizing the BIC. Column 4 reports the weighted mean and standard deviations of the outcome variables in low-saturation control villages (across eligible and ineligible households). Each regression is weighted by inverse sampling weights and contains baseline values of the outcome when available. Standard errors are clustered at the sublocation in Column 1, and calculated following Conley [2008] using a uniform kernel out to $10 \mathrm{~km}$ in Columns 2 and $3 .^{*}$ denotes significance at 10 pct., ${ }^{* *}$ at 5 pct., and ${ }^{* *}$ at 1 pct. level. 
Table 2: Input Prices and Quantities

(1)

Recipient Households Non-recipient Households

$\begin{array}{cc}\mathbb{1} \text { (Treat village) } & \text { Total Effect } \\ \text { Reduced form } & \text { IV }\end{array}$

Panel A: Labor

Hourly wage earned by employees

Household total hours worked, last 7 days

2.44

(1.71)

166.84

(201.20)

$-0.19$

(0.14)

(0.01)

5.55

(4.95)
0.04

(0.04)

1.41

(3.69)

365.44

(290.86)

556.83

(412.34)

$0.19^{*}$

(0.10)

$-4.70$

(3.17)

$-0.10$

(0.09)

0.01

(0.01)

3.13

(8.34)
0.08

(0.10)

$-0.01$

(0.01)

6.36

(13.21)
Control, low saturation mean (SD)

0.70

(0.89)

63.20

$3,952.86$

$(3,148.52)$

1.42

0.06

80.61

(204.36)

Notes: Column 1 reports the coefficient on an indicator for treatment village from a regression using data from eligible households (as classified by the GE census team), and includes an indicator for saturation status of the sublocation (Equation 1). Column 2 reports the total effect on treated households (eligible recipients) from the "optimal" IV spatial regression of each outcome on the amount transferred per capita to a household's own village $v$ (instrumented by village treatment status), and to villages other than $v$ in each $2 \mathrm{~km}$ radii band around the household (instrumented by the share of eligible households assigned to treatment in villages other than $v$ inside the buffer), as in Equation 2. For this analysis, the sample is restricted to eligible households, including between 2,828 and 5,423 observations for variables at the household level, and 2,832 observations at the individual level for wages. Column 3 presents the average spillover effect on eligible households in control villages as well as ineligible households, coming from a stacked spatial regression of each outcome on the amount transferred per capita GDP to each $2 \mathrm{~km}$ radii band around each household (instrumented by the share of eligibles assigned to treatment in each buffer), as in Equation 3. We have between 2,781 to 5,509 observations at the household level and 2,391 wage observations at the individual level. The reported average effect comes from a population-share-weighted average effect experienced by those two groups, and is representative of the average untreated household. The number of radii bands included in Columns 2 and 3 is chosen, as pre-specified, by minimizing the BIC. Column 4 reports the weighted mean and standard deviations of the outcome variables in low-saturation control villages (across eligible and ineligible households). Each regression is weighted by inverse sampling weights and contains baseline values of the outcome when available. In addition, prices are quantity-weighted. That is, wages are weighted by the number of hours worked, land prices by the number of acres purchased, and interest rates by size of each loan. Standard errors are clustered at the sublocation in Column 1 , and calculated following Conley [2008)] using a uniform kernel out to $10 \mathrm{~km}$ in Columns 2 and $3 .{ }^{*}$ denotes significance at 10 pct., ${ }^{* *}$ at 5 pct., and $* * *$ at 1 pct. level. 
Table 3: Enterprise Outcomes

\begin{tabular}{|c|c|c|c|c|}
\hline & (1) & $(2)$ & $(3)$ & (4) \\
\hline & \multicolumn{2}{|c|}{ Treatment Villages } & \multirow{2}{*}{$\begin{array}{c}\text { Control Villages } \\
\text { Total Effect } \\
\text { IV }\end{array}$} & \multirow[b]{2}{*}{$\begin{array}{l}\text { Control, low saturation } \\
\text { weighted mean (SD) }\end{array}$} \\
\hline & $\begin{array}{l}\mathbb{1} \text { (Treat village) } \\
\text { Reduced form }\end{array}$ & $\begin{array}{l}\text { Total Effect } \\
\text { IV }\end{array}$ & & \\
\hline $\begin{array}{l}\text { Panel A: All enterprises } \\
\text { Enterprise profits, annualized }\end{array}$ & $\begin{array}{c}10.46 \\
(24.35)\end{array}$ & $\begin{array}{c}67.53 \\
(41.62)\end{array}$ & $\begin{array}{c}32.91 \\
(37.27)\end{array}$ & $\begin{array}{c}323.39 \\
(691.12)\end{array}$ \\
\hline Enterprise revenue, annualized & $\begin{array}{l}-10.05 \\
(103.02)\end{array}$ & $\begin{array}{l}356.81^{* *} \\
(144.21)\end{array}$ & $\begin{array}{l}244.27^{* *} \\
(108.96)\end{array}$ & $\begin{array}{c}758.52 \\
(2,493.40)\end{array}$ \\
\hline Enterprise costs, annualized & $\begin{array}{l}-11.41 \\
(29.73)\end{array}$ & $\begin{array}{l}97.39^{* *} \\
(38.27)\end{array}$ & $\begin{array}{l}79.48^{* *} \\
(39.42)\end{array}$ & $\begin{array}{c}147.73 \\
(550.11)\end{array}$ \\
\hline Enterprise wagebill, annualized & $\begin{array}{l}-14.72 \\
(26.48)\end{array}$ & $\begin{array}{l}81.69^{* *} \\
(33.76)\end{array}$ & $\begin{array}{r}70.49^{*} \\
(36.52)\end{array}$ & $\begin{array}{c}120.62 \\
(492.11)\end{array}$ \\
\hline Enterprise profit margin & $\begin{array}{c}0.01 \\
(0.02)\end{array}$ & $\begin{array}{c}-0.06^{* *} \\
(0.02)\end{array}$ & $\begin{array}{l}-0.06^{* * *} \\
(0.02)\end{array}$ & $\begin{array}{c}0.44 \\
(0.61)\end{array}$ \\
\hline $\begin{array}{l}\text { Panel B: Non-agricultural enterpri } \\
\text { Enterprise inventory }\end{array}$ & $\begin{array}{l}11.01 \\
(9.14)\end{array}$ & $\begin{array}{l}34.68^{* *} \\
(14.73)\end{array}$ & $\begin{array}{c}16.91 \\
(10.80)\end{array}$ & $\begin{array}{c}192.98 \\
(504.76)\end{array}$ \\
\hline Enterprise investment, annualized & $\begin{array}{c}4.00 \\
(7.05)\end{array}$ & $\begin{array}{c}13.58 \\
(15.39)\end{array}$ & $\begin{array}{c}6.82 \\
(8.65)\end{array}$ & $\begin{array}{c}178.25 \\
(640.98)\end{array}$ \\
\hline $\begin{array}{l}\text { Panel C: Village-level } \\
\text { Number of enterprises }\end{array}$ & $\begin{array}{c}0.01 \\
(0.01)\end{array}$ & $\begin{array}{c}0.02 \\
(0.01)\end{array}$ & $\begin{array}{c}0.01 \\
(0.01)\end{array}$ & $\begin{array}{c}1.12 \\
(0.14)\end{array}$ \\
\hline
\end{tabular}

Notes: Column 1 reports the coefficient on an indicator for treatment village, and includes an indicator for saturation status of the sublocation. Column 2 reports the total effect on enterprises in treatment villages (own-village effect plus across-village spillover) from the "optimal" IV spatial regression of each outcome on the amount transferred per capita to a enterprise's own village $v$ (instrumented by village treatment status), and to villages other than $v$ in each $2 \mathrm{~km}$ radii band around the enterprise (instrumented by the share of eligible households assigned to treatment in villages other than $v$ inside the buffer). Column 3 reports the total effect on enterprises in control villages (across-village spillover only). For each Column, we stack 3 separate regressions for own-farm enterprises, non-agricultural enterprises operated within the household, and non-agricultural enterprises operated outside the household, due to our independent sampling across these enterprise categories (Equations 10 and 11). We have between 9,997 and 10,254 observations for all enterprises, and 2,389 to 2,398 for variables we collect for non-ag enterprises only, and 653 villages. The number of radii bands included in Columns 2 and 3 is chosen, as pre-specified, by minimizing the BIC. Column 4 reports the weighted mean and standard deviations of the outcome variables in low-saturation control villages (across all enterprise categories). Each regression is weighted by inverse sampling weights and contains village-level baseline averages of the outcome variable by enterprise category when available. For monetary values, we convert effects to a per-household level by multiplying the average effect per enterprise in each enterprise category by the number of enterprises in that category, dividing by the number of households in our study area, and summing over all enterprise categories. For the number of enterprises, we run regressions at the village level, where the outcome is the number of enterprises per household in each category, we weight by the number of households in each village and sum up over all enterprise categories. For the profit margin, we weight the effects across all enterprise categories by their share in the economy, and across each enterprise by revenue, so that our estimate represents the effect on the revenue-weighted average enterprise in the economy. Standard errors are clustered at the sublocation in Column 1, and calculated following Conley [2008] using a uniform kernel out to $10 \mathrm{~km}$ in Columns 2 and 3 . $*$ denotes significance at 10 pct., ** at 5 pct., and *** at 1 pct. level. 
Table 4: Output Prices

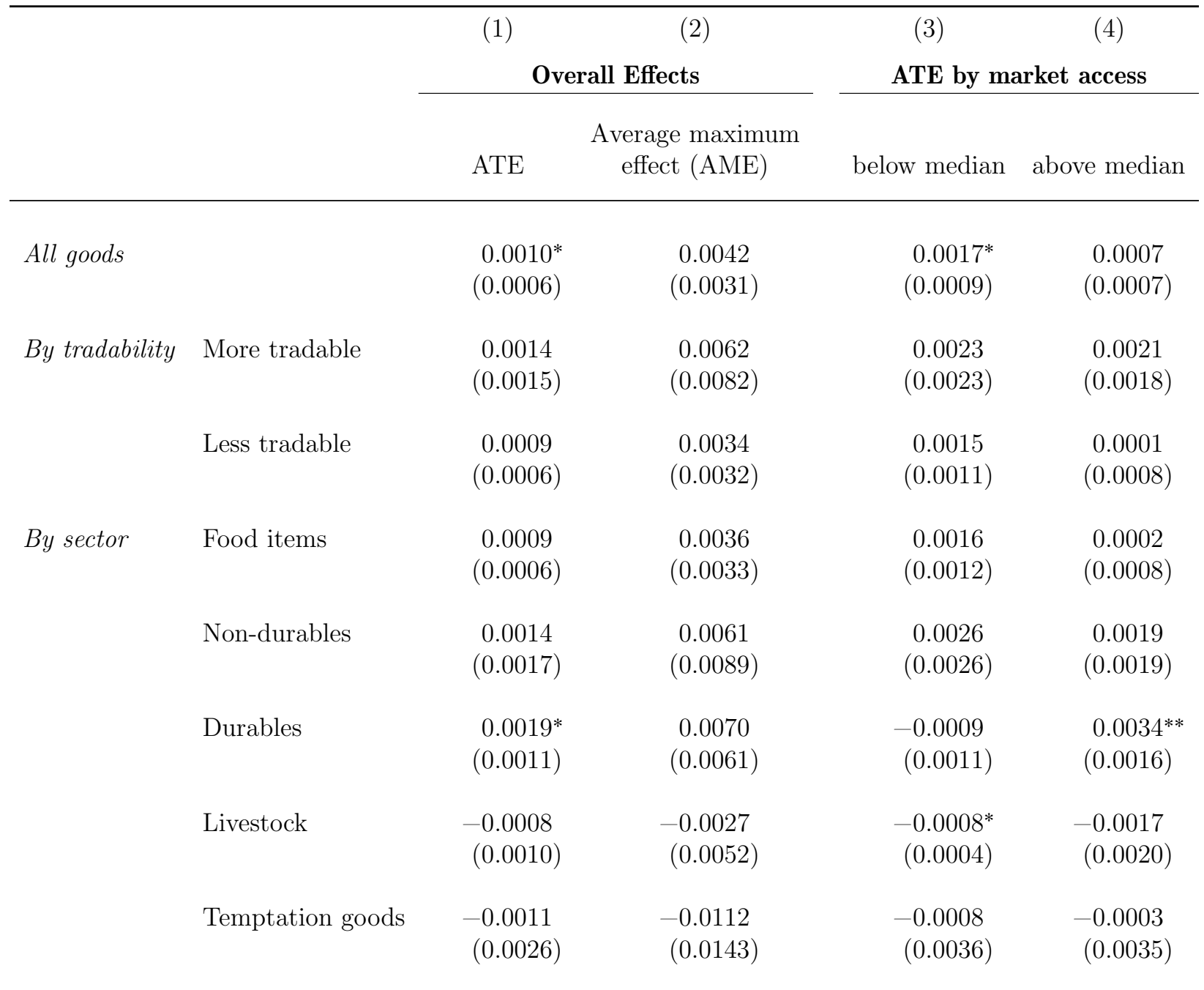

Notes: Each row represents a regression of the logarithm of a price index on the "optimal" number of lags and distance buffers of per capita Give Directly transfers in each buffer. Price indices are based on 311,138 non-missing price quotes for 70 commodities and products. For each product, we take the logarithm of the median price quote in a market-month, and create our market price indices as an expenditure weighted average of these median price quotes across all goods in that marketmonth. Regressions include a panel of 1,734 market-by-month observations. The number of radii bands and lags is chosen sequentially by minimizing the BIC, as pre-specified, for the overall price index, which selects a $4 \mathrm{~km}$ radius; subcomponents use this value as well. Regressions include a full set of market and month fixed effects. Column 1 reports the implied ATE, calculated by evaluating the "optimal" regression specification at the average level of treatment intensity between September 2014 and March 2017, the time during which transfers went out. Column 2 reports the average maximum effect, calculated at the average across all markets of the month in which the largest per capita transfers went into a market's neighborhood (up to the largest buffer selected by the algorithm). Columns 3 and 4 break down the ATE by market access, defined as $M A_{m}=\sum_{r=0}^{10} r^{-\theta} N_{r}$, where $\theta=8$ and $N_{r}$ is the population in in the $r-2$ to $r \mathrm{~km}$ buffer around each market. Standard errors (in parentheses) are as in and we allow for spatial correlation up to $10 \mathrm{~km}$ and autocorrelation up to 12 months. $*$ denotes significance at 10 pct., ${ }^{* *}$ at 5 pct., and $* * *$ at 1 pct. level. 


\section{Table 5: Transfer Multiplier Estimates}

\begin{tabular}{|c|c|c|c|}
\hline & $\begin{array}{c}(1) \\
\mathbb{M} \\
\text { Estimate }\end{array}$ & $\begin{array}{c}(2) \\
\mathrm{H}_{0}: \mathbb{M}<0 \\
p \text {-value }\end{array}$ & $\begin{array}{c}(3) \\
\mathrm{H}_{0}: \mathbb{M}<1 \\
p \text {-value }\end{array}$ \\
\hline Panel A: Expenditure multiplier & $\begin{array}{c}2.53 \\
(1.42)\end{array}$ & $0.04^{* *}$ & 0.14 \\
\hline Household non-durable expenditure & $\begin{array}{c}1.17 \\
(1.32)\end{array}$ & 0.19 & \\
\hline Household durable expenditure & $\begin{array}{c}0.81 \\
(0.05)\end{array}$ & $0.00^{* * *}$ & \\
\hline Enterprise investment & $\begin{array}{c}0.48 \\
(0.42)\end{array}$ & 0.13 & \\
\hline Enterprise inventory & $\begin{array}{c}0.07 \\
(0.03)\end{array}$ & $0.02^{* *}$ & \\
\hline Panel B: Income multiplier & $\begin{array}{c}2.28 \\
(1.73)\end{array}$ & $0.10^{*}$ & 0.23 \\
\hline Enterprise profits & $\begin{array}{c}1.47 \\
(1.28)\end{array}$ & 0.13 & \\
\hline Household wage bill & $\begin{array}{c}0.68 \\
(1.15)\end{array}$ & 0.27 & \\
\hline Enterprise capital income & $\begin{array}{c}0.09 \\
(0.17)\end{array}$ & 0.31 & \\
\hline Enterprise taxes paid & $\begin{array}{c}0.04 \\
(0.03)\end{array}$ & $0.08^{*}$ & \\
\hline \multicolumn{4}{|c|}{ Panel $C$ : Expenditure and income multipliers } \\
\hline Average of both multipliers & $\begin{array}{c}2.40 \\
(1.38)\end{array}$ & $0.04^{* *}$ & 0.15 \\
\hline Joint test of both multipliers & & $0.02^{* *}$ & $0.07^{*}$ \\
\hline
\end{tabular}

Notes: Results are from the joint estimation of expenditure and income multipliers. Column 1 reports point estimates of both multipliers and their respective components. Each component is estimated individually and the multiplier is obtained by aggregating components as described in the main text. Effects of the cash infusion on flow variables (non-durable consumption, investment, wages, profits, capital income, and taxes) are obtained by dynamically estimating effect sizes over 29 months after the first transfer and computing the integral under this curve (Equation 7). Effects on remaining stock variables are the estimated the total endline treatment effects (Equations 2, 3and 11). Transfer amounts and outcome variables are deflated to January 2015 using the overall consumer price index in the geographically closest market. Standard errors are computed from 2,000 replications of a wild clustered bootstrap, which re-allocates within-sublocation Rademacher-perturbed residuals from the main population regressions to fitted outcome values to create perturbed samples. Columns 2 and 3 conduct one-sided tests of each multiplier estimate $\mathbb{M}$ against 0 and 1 respectively, using the bootstrapped distributions of $\mathbb{M}$. Panel $\mathrm{C}$ conducts two tests regarding both multipliers. The first row computes the average of both estimates and conducts tests on this average using the same bootstrap procedure. The last row reports p-values from joint tests of both multipliers against the same nulls. ${ }^{*}$ denotes significance at 10 pct., ${ }^{* *}$ at 5 pct., and ${ }^{* * *}$ at 1 pct. level. 